\title{
THE EVOLUTION OF ENERGY ABSORPTION SYSTEMS FOR CRASHWORTHY HELICOPTER SEATS
}

\author{
STANLEY P. DESJARDINS \\ SPDESJARDINS@EARTHLINK.NET \\ PRESIDENT \\ SAFE, INC \\ TEMPE, ARIZONA
}

\begin{abstract}
The objective of this paper is to trace the development history of the energy absorbing systems used on crashworthy helicopter seats from their beginnings in the early 1960's to the current time. Its purpose is to assess the state-of-the-art of these systems and to prescribe the path of future needs and efforts. This paper emphasizes the evolution of energy absorption systems. It summarizes early investigatory and developmental concepts as well as the evolutionary process that led to the systems that are being produced and fielded in today's helicopters. It discusses the many different kinds of energy absorbing concepts that have been suggested, developed, and fielded by several different seat suppliers located around the world. It also discusses the different approaches used to satisfy the many different requirements, military, armored and unarmored, as well as civil. It discusses advanced concepts as well as work that remains to be done in order to provide the best possible crash protection to occupants of current and future helicopters. ${ }^{1}$
\end{abstract}

\section{INTRODUCTION}

The need for improved seats in helicopters was initially established by the work of the Aviation Crash Injury Research (AvCIR) Division of The Flight Safety Foundation, during the late 1950's and early 1960's. AvCIR was later renamed Aviation Safety Engineering

\footnotetext{
${ }^{1}$ Presented at the American Helicopter Society $59^{\text {th }}$ Annual Forum, Phoenix, Arizona, May 6-8, 2003. Copyright (C) 2003 by the American Helicopter Society International, Inc. All rights reserved.
}

and Research (AvSER) in the early 1960's. This nonprofit organization was originally established in Phoenix as a Division of the Flight Safety Foundation, Inc to investigate crashes to determine the cause of injuries. Previous investigations had been conducted only to determine the cause of the crash rather than the cause of injuries, and as a result, little was known about the injury causing mechanisms. It was determined that many improvements were needed to adequately restrain the occupant, to keep the seats attached to aircraft structure, and to provide for limiting the loads applied to the occupant during crashes producing loads predominately parallel to the occupant's spine. It was concluded that a properly restrained human occupant could survive the loading applied in the forward (X) and lateral (Y) directions in survivable accidents, but not in the vertical (Z) direction. Limiting these loads was necessary to improve the chance of survival and to minimize the chance of spinal fracture and the risk of paraplegia. The load limiting function was to be provided by allowing the seat and occupant to move (stroke) at loads just under the humanly tolerable limit over the maximum distance available in the aircraft to extend the survivable environment as far as possible.

During the 1960's and early 1970's considerable work was conducted to develop workable concepts and then to develop the design criteria and specifications for both design and qualification of the seats. At present almost all of the military and many of the civil helicopters in the world are equipped with crashworthy/energy absorbing seats. Several different seat suppliers have elected to offer these seats and all have used the concepts and criteria defined by the early work as documented in the referenced material. At 
first, most of the seats used energy absorbing devices that applied a single, fixed approximately constant, load-displacement characteristic to decelerate the occupant and are referred to as Fixed Load Energy Absorbers (FLEA). This fixed load was designed for the $50^{\text {th }}$ percentile seat occupant in order to maximize the effectiveness over the weight range of the users. This meant that lighter occupants received a higher deceleration level (G's) than heavier occupants, while heavier occupants received a lower deceleration but used more stroke. Thus, the lighter occupants were at a higher risk of spinal injury due to the load applied during stroking, and the heavier occupants, although decelerating at a lower level throughout the stroke, were at a higher risk of bottoming out (exhaustion of the stroke distance). To correct these weaknesses manually adjustable, or Variable Load, Energy Absorbers (VLEA) were developed to allow the occupant to adjust the energy absorber limit load to match his or her weight thus producing the same level of protection for all sizes of occupants.

One seat supplier incorporated VLEA's while others have developed and produced seats that use a loaddisplacement profile that is not constant but varies with stroke in an attempt to take advantage of the "springmass" characteristics of the human body and to provide a more efficient energy absorbing process. These are not variable load, but exhibit a fixed single profile load-displacement characteristic regardless of occupant weight. Consequently they are referred to as Fixed Profile Energy Absorbers (FPEA). This approach has produced seats that are certified to civil standards while others, using a somewhat different approach, have been qualified for military use. Civil certification requires testing with only a $50^{\text {th }}$ percentile test dummy and does not consider the range of occupant sizes that will be using the seats. Efforts to develop seats with the profiled load-deflection characteristic for military use, where testing requires use of both large and heavy as well as small and light dummies in addition to the $50^{\text {th }}$ percentile, have produced differing results as explained in more detail later in this paper.

The next major advancement in energy absorption is the Variable Profile Energy Absorber (VPEA) in which the limit loads of the profile can be increased or reduced to match the weight of each specific occupant. The ultimate device is the Automatic Energy Absorber (AEA). A research program to investigate and develop such technology was recently sponsored by the U. S. Navy. The resulting systems will weigh the occupant, set the appropriate limit load for the occupant's weight, and then will decelerate the occupant with a special nonlinear load-deflection profile developed to improve the efficiency of the process.

Use of an AEA will provide the maximum amount of protection to a larger range of occupants and in more energetic crashes than can be provided by other more common and currently used energy absorbing systems.

\section{CRASH SCENARIO, VERTICAL DIRECTION}

\section{Design Criteria}

Survivable crash scenarios for U.S. Army helicopters were developed during studies conducted during the late 1950's and early 1960's and initially documented in the Crash Survival Design Guide. The Aircraft Crash Survival Design Guide, containing criteria for the design of all crashworthiness features, including seats, was first published in 1967 as Technical Report 67-22 [1]. Updated revisions were published in 1970, 1971, 1979 and 1989 [2,3,4,5]. Detailed requirements for military crew seats were further defined in MIL-S58095(AV), [6], which was first released in 1971 with the "A" revision being released in 1986. Detailed requirements for military troop seats were defined in MIL-S-85510(AS), [7] which was issued in 1981, and civil rotorcraft seats in SAE, AS8049 [8] which was first issued in 1990 and revised in 1997. Federal performance requirements for civil helicopters are established in the United States Code of Federal Regulations, Title 14, Parts 27 and 29 [9,10].

This paper deals only with energy absorption in the vertical ( $\mathrm{Z}$ axis relative to the seat and occupant) crash load direction and the systems developed to attenuate, or limit, the resulting loads on occupants of these military and civil helicopters. The deceleration-time relationships (pulses) developed for the design of these systems are shown in Figures 1-a, -b, and -c below.

Since a human cannot survive the resultant loading imposed by these deceleration environments in a direction parallel to the spine ( $\mathrm{Z}$ axis) load attenuation must be employed. The load, or force, decelerating the occupant must be limited such that the applied loads are of a humanly tolerable time-magnitude relationship. 
(a) Military Helicopter Cockpits

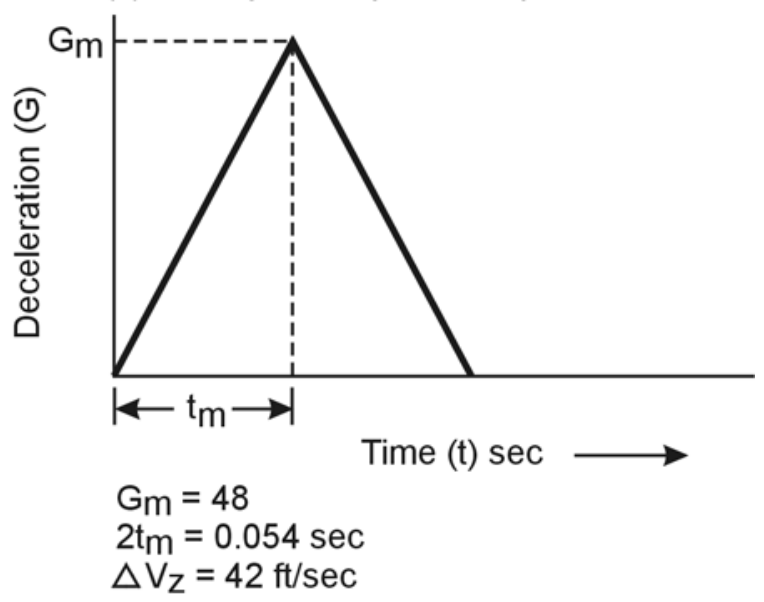

(b) Military Helicopter Cabin

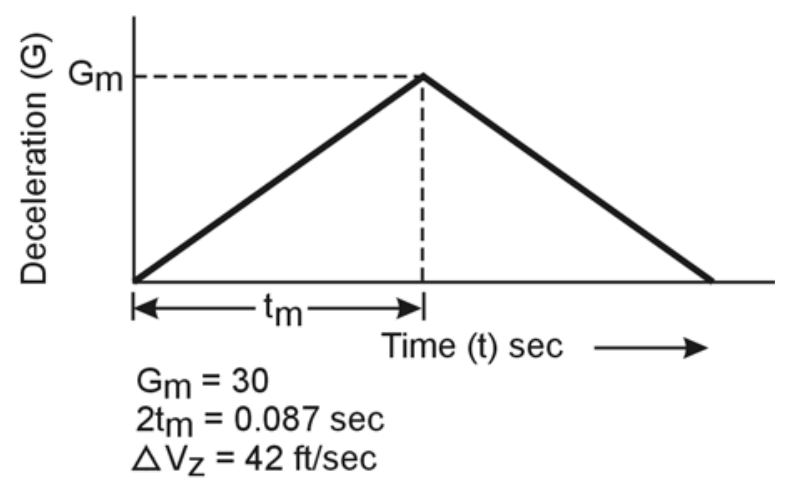

(c) Civil Helicopters

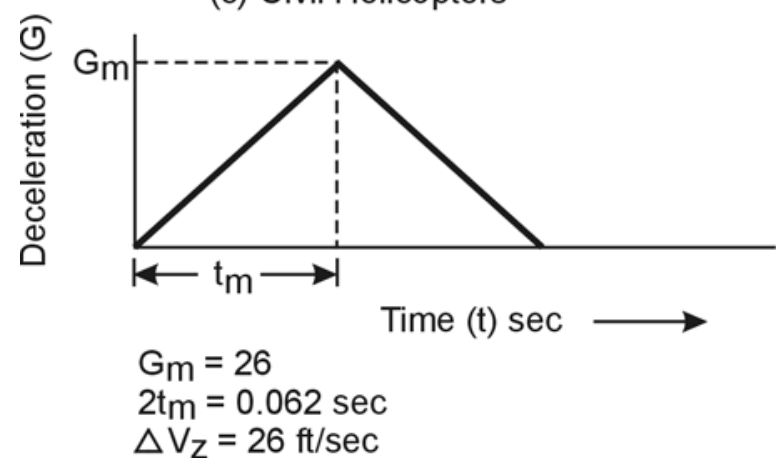

Figure 1.

Deceleration-Time Relationships for Military and Civil Helicopters

It was determined in the late 1960's and early 1970's through analysis and testing that the limit load (that load at which the energy absorber would start and continue to stroke) of energy absorbing systems had to be set lower than originally thought $(18 \mathrm{G})$ based on observation of seat performance relative to the tolerance data assembled by Eiband [11, also presented in $1,2,3,4,5$ ] in order to account for dynamic overshoot and to keep the load-duration environment in the humanly tolerable range. After further investigation it was determined that the load factor used to establish the energy absorbing limit load should be $14.5 \mathrm{G}$ [12]. It was therefore recommended that the energy absorption systems for military helicopter seats be sized to stroke at 14.5 times the effective weight of the $50^{\text {th }}$ percentile occupant plus the weight of the stroking portion of the seat, which obviously included the weight of the cushions and the restraint system. This load factor was later verified by cadaveric testing and analysis [13].

\section{Energy Absorption}

The most efficient and therefore the most effective process for limiting loads is one that absorbs or dissipates energy rather than one that stores it [14]. More efficient processes require shorter strokes, or less displacement, in absorbing the energy and limiting loads to within the human tolerance range. A simplified relationship to predict this stroke was developed and first published in 1967 [1]. Figure 2-a, $\mathrm{b}$, and -c show the displacement-time, velocity-time, and distance-time relationships involved. It is assumed that the airframe experiences the triangular deceleration pulse shown and that the seat/occupant system is load-limited at the load factor identified as $\mathrm{G}_{\mathrm{L}}$ in Figure 2-a. The seat/occupant response is represented by the dotted line; whereas, the floor deceleration of the helicopter is represented by the solid line. This analysis assumes that the occupant is restrained rigidly to a rigid seat up to the point that the load limit is reached since there is no variation in the two onset rates. Further, it assumes that the occupant is rigid and attached rigidly to the moving portion of the seat for the entire stroke. Note that for the rigid seat/occupant system assumed, this process is as efficient as can be achieved for the limit load factor selected since the dotted line coincides with the solid line up to the limit load $G_{L}$. Once the seat-occupant system reaches the limit load $G_{L}$, the seat strokes at a constant load factor (and load) as shown by the dotted line. It can be seen in Figure 2-b that the occupant's velocity is being reduced at a slower rate than that of the airframe and in Figure 2-c that the occupant has stroked, or moved, a larger distance than the airframe. The difference between the airframe displacement and the seat/occupant displacement is the stroke, or displacement of the seat. 


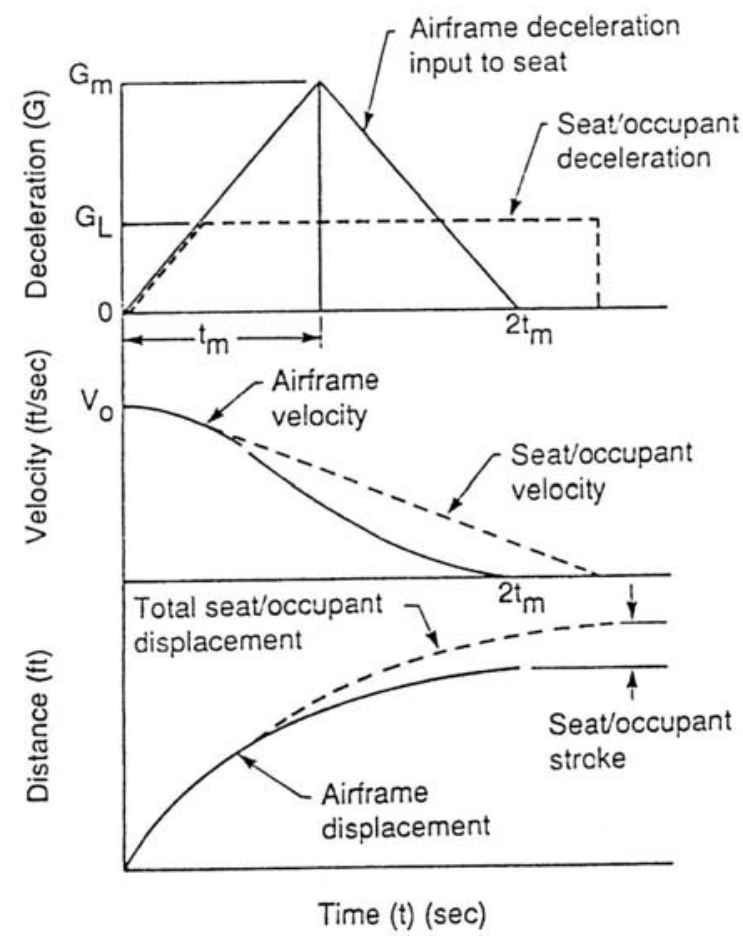

Figure 2.

Deceleration-Time, Velocity-Time, and Distance-Time Relationships for Airframe and Seat/Occupant

This process is often misunderstood by thinking that the energy absorption mechanism of the seat absorbs all of the energy associated with the impact velocity of the seat and occupant. Actually, part of the energy associated with the initial occupant and seat velocity is absorbed by the crushing of the airframe and deformation of the impacted surface, and only the energy associated with the difference in velocity between the airframe and seat is absorbed by the seat. Again, the reason there is a difference is that the seat and occupant are decelerating at a slower rate than the airframe, thus reducing the loads imposed on the seat and occupant.

The relationships that have been developed for this idealized situation are as follows:

$\mathrm{S}=G_{m} g t_{m}^{2}\left(\frac{1}{2} k+\frac{k}{2}-0.0417 k^{3}-1\right), k \leq 0.0586$
Where: S = stroke or deformation, in.

$\mathrm{G}=$ gravitational constant $\left(32.2 \mathrm{ft} / \mathrm{sec}^{2}\right.$ or 386.4 in. $/ \mathrm{sec}^{2}$ )

$\mathrm{t}_{\mathrm{m}}=$ time to $\mathrm{G}_{\mathrm{m}}$, sec.

$\mathrm{G}_{\mathrm{m}}=$ Maximum deceleration, $\mathrm{G}$

$\mathrm{G}_{\mathrm{L}}=$ Limit-load deceleration, $\mathrm{G}$

$\mathrm{k}=$ constant $=\mathrm{G}_{\mathrm{L}} / \mathrm{G}_{\mathrm{m}}$.

As an example, consider a triangular pulse representing a change in velocity of $42 \mathrm{ft} /$ per sec. with:

$$
\begin{aligned}
& \mathrm{G}_{\mathrm{m}}=48 \mathrm{G} \\
& \mathrm{T}_{\mathrm{m}}=0.027 \mathrm{sec} \\
& \mathrm{G}_{\mathrm{L}}=14.5 \mathrm{G} \\
& \mathrm{k}=14.5 / 48=0.302 .
\end{aligned}
$$

Then from equation (1):

$$
\mathrm{S}=10.9 \mathrm{in} .
$$

The total stroke involved in stopping the airframe in this same scenario can be determined from the following relationship:

$$
\mathrm{S}=\frac{V_{0}^{2}-V_{f}^{2}}{2 g \bar{G}}
$$

Where:

$$
\begin{aligned}
& \mathrm{S}=\text { stroke or distance traveled, } \mathrm{ft} . \\
& \mathrm{V}_{0}=\text { Initial velocity, } \mathrm{ft} / \mathrm{sec} . \\
& \mathrm{V}_{\mathrm{f}}=\text { Final velocity, } \mathrm{ft} / \mathrm{sec} . \\
& \mathrm{g}=32.2 \mathrm{ft} / \mathrm{sec}^{2} \\
& \mathrm{G}=\text { Average deceleration of the fuselage, }(\mathrm{G}) \text {. }
\end{aligned}
$$

For comparison purposes if we assume that the airframe were to crush at the average deceleration of $14.5 \mathrm{G}$ (picked to match the limit load of the seat, but far too high for a typical airframe) then for the same pulse described above, the stroke of the airframe would be:

$$
\mathrm{S}=1.89 \mathrm{ft} \text {. (or } 22.67 \mathrm{in} .)
$$

The significance of this is that as the occupant/seat is less rigidly coupled to the aircraft structure because of occupant flexibility/compressibility, deflection of cushions, or structural flexibility, the process gets less efficient and more stroke is needed. If, for example, the airframe had completely decelerated by the time the occupant began to decelerate, the full 22.67 inches 
of stroke would be needed to decelerate the occupant stroking at the design limit load factor of $14.5 \mathrm{G}$.

A comprehensive discussion of fuselage crushing, occupant response and dynamic overshoot is outside the scope of this paper; however, it was felt that at least a brief mention was warranted based on misunderstandings that have occurred in the past.

\section{Crash Load Attenuator Concepts}

As energy absorbing seat technology was developed (and eventually required by Federal regulation) for helicopters, many energy absorbing mechanisms or concepts were proposed, analyzed, tested, discarded, adapted, developed and fielded in operational systems. All adopted systems are versions of, and/or improvements of, previously considered concepts. Some of the older concepts are discussed in all but the first edition of the Crash Survival Design Guide $[2,3,4,5]$. Many of the original reports including testing and evaluation efforts are referenced in the References Sections of these Guides. For general information, the most common concepts that were suggested, analyzed or tested during the 1960's and 1970's are listed below:

- Crushable Column

- Rolling Torus

- Inversion Tube

- Cutting or Slitting

- Tube and Die

- Rolling/Flattening a Tube

- Strap, Rod, or Wire Bender

- Wire-Through-Platen

- Deformable Links

- Elongation of Tube, Strap, or Cable

- Tube Flaring

- Housed Coiled Cable

- Bar-Through-Die

- Hydraulic

- Pneumatic

All of the concepts suggested and/or investigated are not discussed in this paper, but most of those that have been developed and fielded, the first nine listed above, or versions of them, are mentioned. The concepts discussed in more detail below are the Crushable Column; Rolling Torus; Inversion Tube; Cutting or Slitting; Tube and Die; Strap, Rod, or Wire Bender; and the Deformable Link.
Crushable Columns: Probably the simplest and most obvious type of energy absorbing process is the crushing of a column or tube made from aluminum or paper honeycomb as shown in Figure 3.

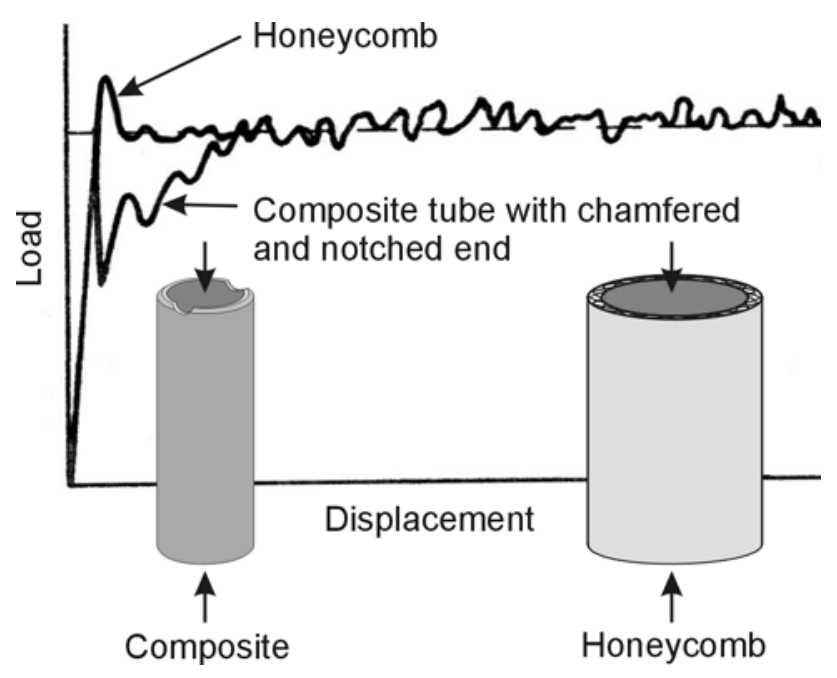

Figure 3.

Two Types of Crushable Column Energy Absorbers

When used as a separate device in energy absorbing seats, the column was typically placed inside a metal cylinder and a second capped cylinder (piston) that applied the load to the energy absorbing column was positioned inside the outer tube and against the crushable material. The load-deflection characteristics were produced by crushing the column. The device was first used in landing struts for the Sikorsky S-58, S-61, and the S-62 helicopters, but was later also adapted as the energy absorber for the pilot seat used on the early models of the Bell 222 Light Twin Helicopter. The honeycomb material used in the seats was later replaced by Bell with a small tubular column of composite material that was not only smaller but also lighter.

The composite material provided a somewhat different energy absorbing process than did the honeycomb, depending on the angle on the face of the die that was forced into the end of the composite tube [15]. For flatter die faces, the end of the column needed to be beveled and slotted to help initiate buckling and crushing. For larger angles, the load-time characteristics could be a result of hoop tension in the tube wall as well as wall crushing. 
Rolling Torus: Early versions of this energy absorber consisted of a number of torus elements located in the annular space between two telescoping cylinders. Development and modification of this concept resulted in substitution of a continuous helix of stainless steel wire for the tori elements, Figure 4.

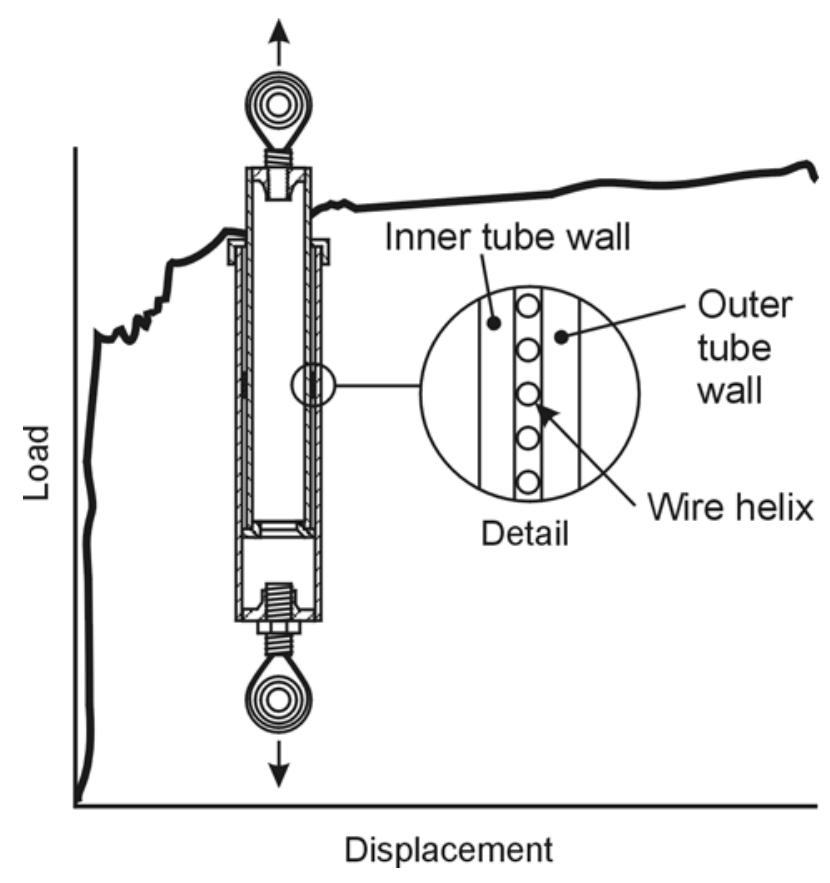

Figure 4.

Rolling Torus Energy Absorbing Concept

The interference fit between the cylinders and tori, or wire, assured rolling rather than sliding as loads were applied. The cyclic plastic deformation of the rolling tori or wire helix effects the energy absorption process. Commercial versions of this energy absorber were offered by ARA of City of Industry, California and were referred to as the TOR SHOK ${ }^{\mathrm{TM}}$. They were first used in a rather early stage of crashworthy seat development in a design for the $\mathrm{CH}-46$ helicopter, and later somewhat more successfully, in seats built for several lots of the UH-60 Black Hawk helicopter.

Inversion Tubes: This device uses the force required to invert, turn inside out or outside in, a length of metal tubing. The device was developed by the General Motors Research Laboratories [16], for incorporation into automobile steering columns to produce controlled collapse loads. It was not used for this application as a cheaper, albeit heavier, approach was chosen. In the 1970's Simula (Simula Inc., of Phoenix, Arizona) developed and refined the concept for use in energy absorbing seats for helicopters, (Figure5).

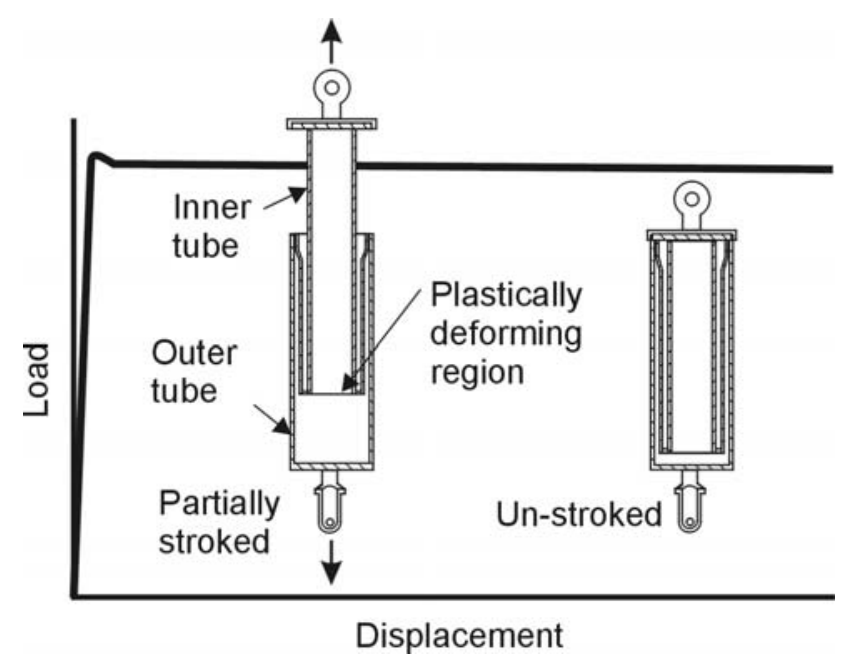

Figure 5.

Inversion Tube Energy Absorber Concept

The first generally successful energy absorbing crew seat fielded was the Simula designed and manufactured seat for the UH-60 Black Hawk helicopter, which used the inversion tube energy absorber. The Simula seat was used in the early and in the later manufactured lots of Black Hawks while the ARA seat using the rolling torus type of energy absorber was used in the intervening lots. The inversion tube is very reliable and repeatable. It has been used in most of Simula's military seats including seats for the UH-60 Black Hawk and Derivatives, AH-64A and D Apache, SH-60 Seahawk and Derivatives, SH-3 Sea King, CH-53 Sea Stallion, EH101 and Derivatives, the UH-1Y, AH-1Z, RAH-66 Comanche, and the HH-60J and $\mathrm{H}$ helicopters.

Cutting or Slitting: Several different metal cutting devices were considered in the '60s and '70s. Concepts using a single point tool to slit a tube wall as well as a broader chisel type cutting edge to machine a wider cut from a block or plate were evaluated, Figure 6. The single point tool approach was used on energy absorbing landing gear, but, as far as is known by the author, not on seats. Early versions of these types of energy absorbers were not felt to offer the repeatability and efficiency needed for the aircraft seat application. 

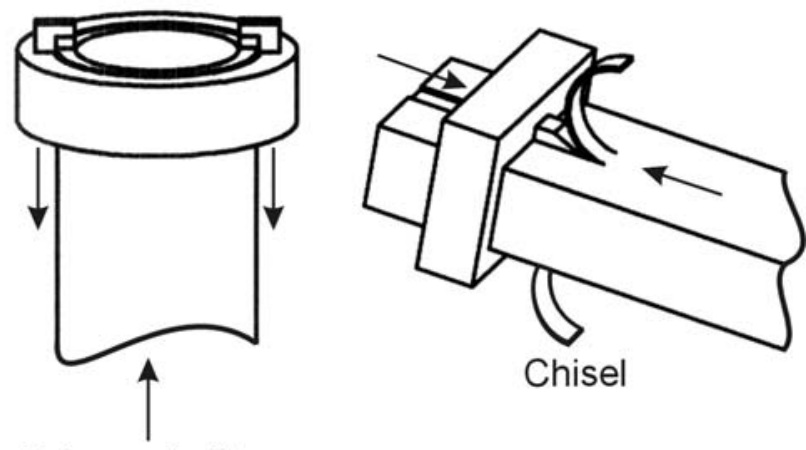

Tube wall slitter

Figure 6.

Cutting or Slitting Energy Absorber Concepts

In the 1990's Martin Baker (Martin Baker Aircraft Company, Ltd, England) successfully developed and fielded several systems using the metal cutting approach. These included seats for the European French/German Tiger Attack helicopter, the South African Rooivalk Attack helicopter, a Utility Seat (troop seat) and an Integral Energy Absorbing System that used the metal cutting approach.

Tube and Die: This device uses the force required to expand or reduce the diameter of a tube as a hardened die is drawn through the tube or the tube is drawn through the die. Energy is absorbed by forcing the tube to increase in diameter as the die is drawn through it or to decrease in diameter as it is drawn through the die. The force required to overcome friction also contributes to the energy absorbing process for this device, Figure7. The figure shows a concept that reduces the diameter of the tube as it is drawn through the die. It is the type of energy absorber used on the Martin Baker armored crew seats for the Agusta A129 Attack helicopter.

A second type of tube and die energy absorber is a concept in which a tube is drawn through a set of rollers, or a die. The roller concept illustrated in Figure 8 is one that can support loading and strokes in either direction. The concept, which draws a tube through a die, is used by IAI (IAI Golan Industries, Israel Aircraft Industries Ltd., Israel). With either roller or die concept, the energy is absorbed by plastically bending the walls of the tube in the radial direction flattening the tube. With concepts that use a die, a greater percentage of the energy is absorbed through friction than for those using rollers.

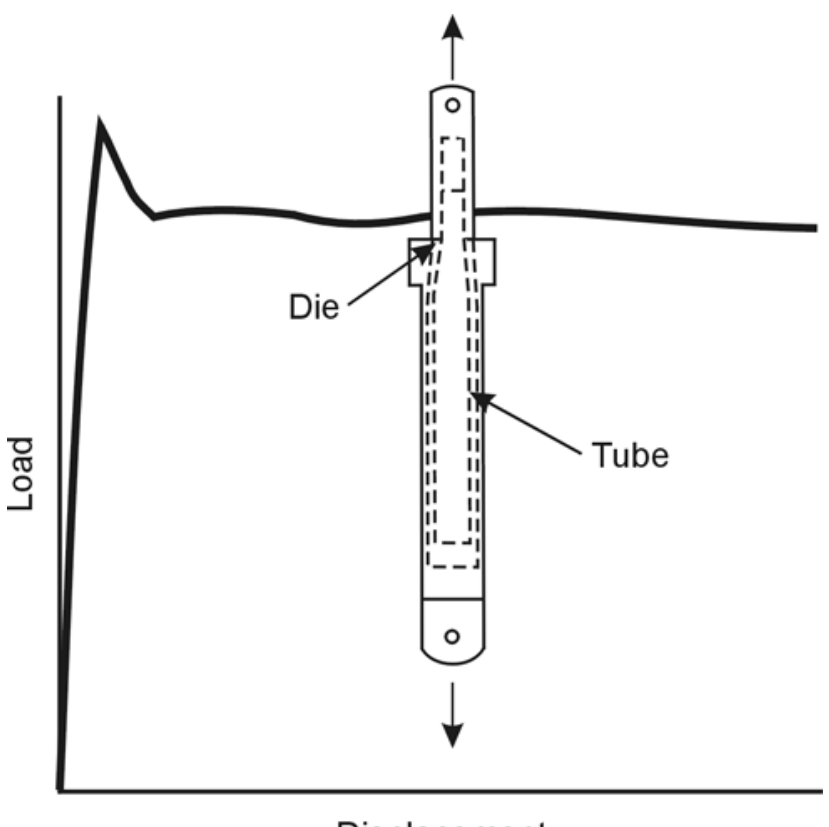

Displacement

Figure 7.

Tube and Die Energy Absorber Concepts

(Expands or Contracts a Tube)

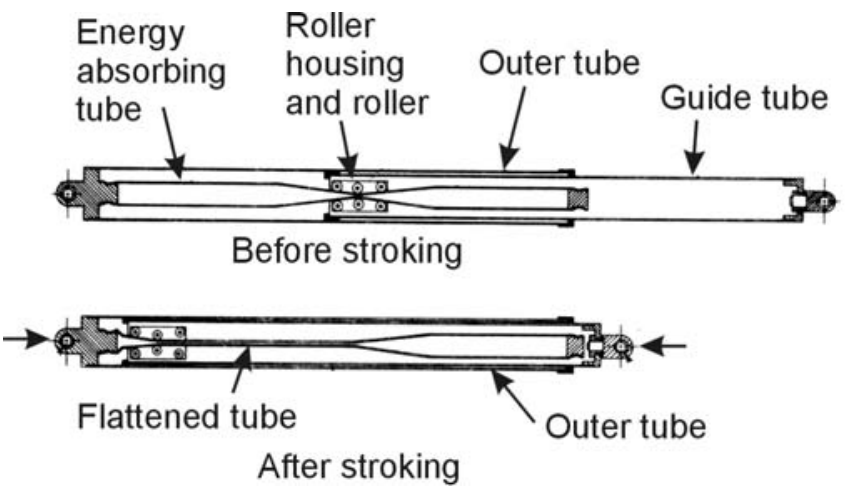

Figure 8.

Tube and Die or Roller Energy Absorber Concept

(Flattens a Tube)

Wire or Strap Bending: This concept uses the force required to bend a metal wire or strap. It can be as simple as drawing a wire or strap through offset rollers or pins, or bending a metal strap. In their simplest configuration, the wire bender devices did not have the 
ability to sustain loads in both directions. However, by anchoring both ends of the wire and attaching the seat bucket to the rollers, loads in either direction could be sustained.

Two variations of the wire bending device have been developed and used in ceiling and floor mounted troop seats. Both variations of the wire bending energy absorber are shown in Figure 9.

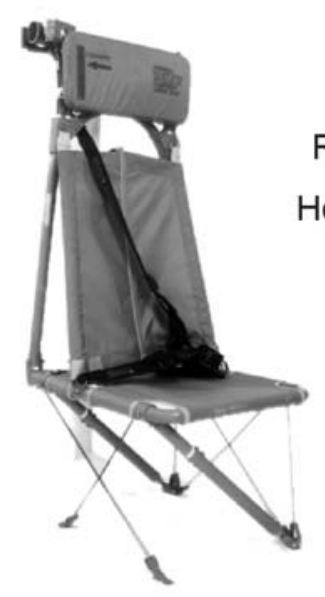

(a)

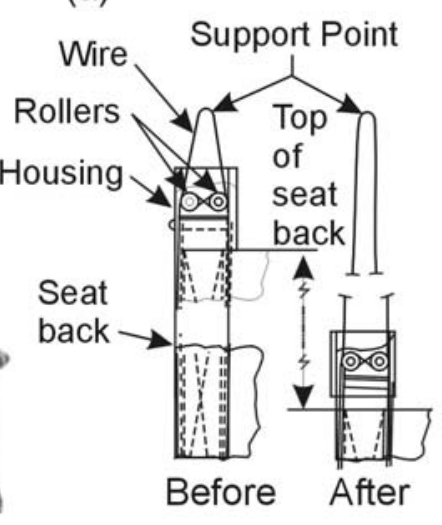

(b)
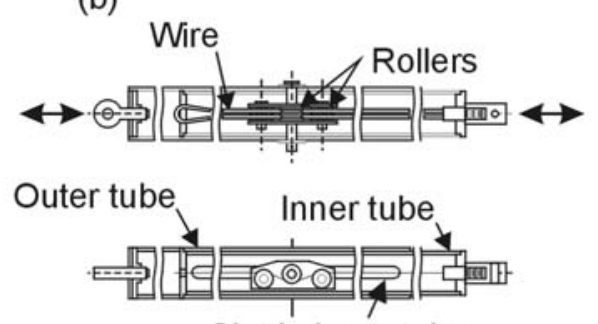

Slot in inner tube

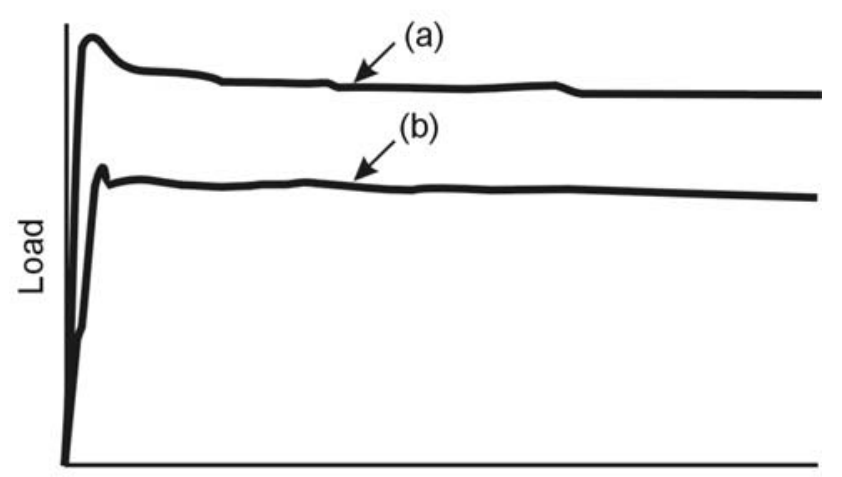

Displacement

Figure 9.

Wire Bender Energy Absorbers Concepts
The configuration shown in Figure 9-a is only capable of functioning in tension. The configuration shown Figure 9-b is capable of functioning in tension or compression. The device shown in Figure 9-b is contained in two telescoping aluminum tubes. A cap is placed on the inner end of the inner tube. Wire is looped through the cap, and the two free ends are secured to a stud in the outer end of the inner tube. A trolley consisting of three rollers sandwiched between two plates bends the wire as the trolley moves back or forth on the wire. The trolley is pinned to the outer tube, and slots are provided in the inner tube wall to allow passage of the pin connecting the trolley to the outer tube.

Seats using this type of device are now installed in several helicopters. The wire bender designs shown are used in the UH-60 Black Hawk troop seats and variations are used in several of Simula's civil helicopter seats. A more complex version described later is used in the Simula V-22 armored crew seat. Skyline (Skyline Industries, Inc., Fort Worth, Texas) uses another variation of wire bending energy absorber in their two seat designs. Fischer (Fischer + Entwicklungen GmbH \& Co. KG, Germany) uses strap bending energy absorbers in all of their seats.

Energy Absorbing Links: Deformable links were first studied for use as energy absorbers by researchers in the Netherlands in the early 1960's [17]. The link configurations investigated were formed in "S" shapes in an effort to get the longest stroke possible from a simple straightening of the material, Figure 10 . The cross-sections of the various portions of the links were varied to obtain the desired load-displacement characteristic while restraining the deforming link to the original plane of the material.

This type of simple device is used today in seats where rigidity of the system is desired coupled with very short stroke requirements. They are used in some civil helicopter seats and most recently, in ground vehicle seats designed to absorb the shock of mine blasts. The typical load-displacement curve for the device shown is presented in the figure, but the link can be varied to yield almost any load-deflection characteristic desired. 


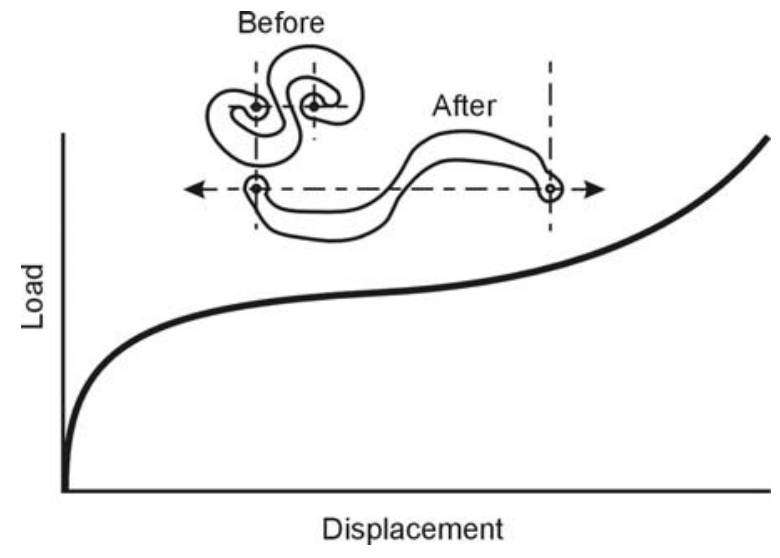

Figure 10.

Deformable Link Energy Absorber Concept

FIXED LOAD ENERGY ABSORBERS (FLEA)

\section{Selection and Application}

During the early phases of energy absorbing seat development, all of the concepts mentioned as well as others were scrutinized for their ability to provide the length of stroke required while producing a nearly constant load during the stroke. The term "specific energy" was used as a measure of efficiency. It was calculated by multiplying the average stroking force over the stroke distance by the stroke distance and dividing the result by the weight of the device. Since the area under the load-displacement characteristic reflects the energy absorbed during the displacement, and since the maximum limit load $\left(\mathrm{L}_{\mathrm{L}}\right)$ was fixed at 14.5G, the maximum amount of energy that could be absorbed within the available stroke was by a device that produced a constant load. Figure 11 illustrates the concept. It is apparent that there is more area under curve ' $a$ ' than there is under curves ' $b$ ' or ' $c$ '. Concepts were therefore sought that displayed the most constant load-displacement characteristic. The concept that produced the flattest, most constant loaddisplacement characteristic at that time was the inversion tube. Further, it was judged to be reliable, predictable and reasonably efficient in terms of specific energy. As a result Simula chose the inversion tube as the energy absorbing approach for most of its early military seat designs.

As other seat suppliers began to develop designs, other concepts were chosen. The following presents examples of crashworthy seats containing fixed load energy absorbing (FLEA) systems.

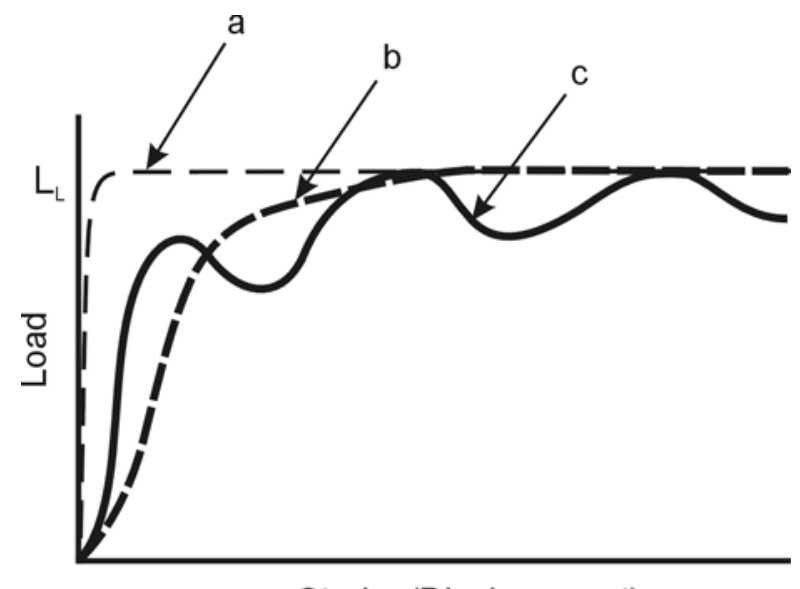

Stroke (Displacement)

Figure 11.

Comparison of Different Load Displacement Characteristics

\section{Examples of Seats}

Simula Seats: Simula seats use either the inversion tube energy absorber or the wire bender. The type of device is presented in the figure captions. In Simula seat designs, the buckets are attached to guides through sliding or roller bearings, and are suspended in the vertical position by the energy absorbing system. In a crash, the loads rise until they reach the limit load of the energy absorbers and then began to stroke, holding the load constant as the stroke progresses until the energy is absorbed and the system has come to rest. Examples of the Simula seats are shown in Figures 12 16.

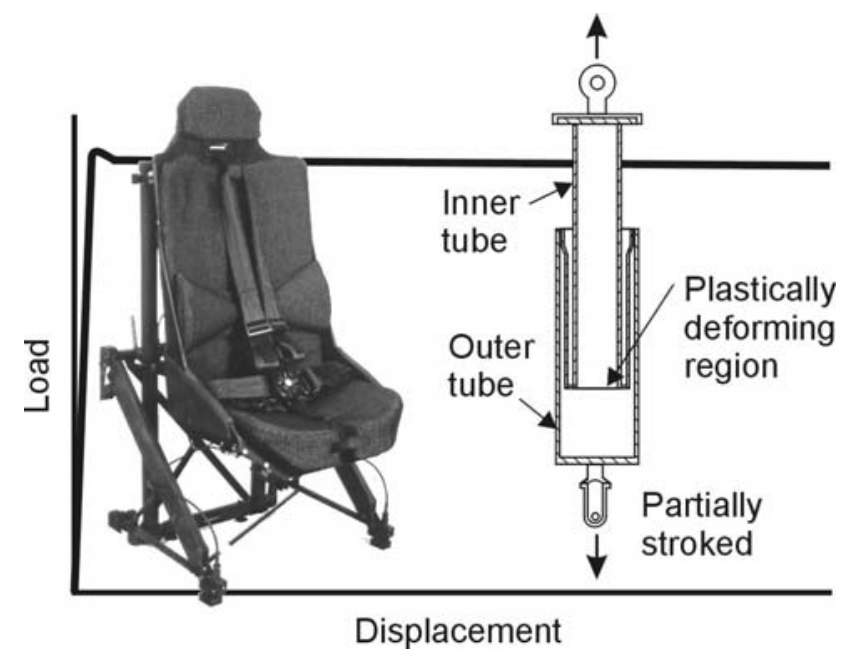

Figure 12.

UH-60 Black Hawk Armored Crewseat, Inversion Tube Energy Absorbers 


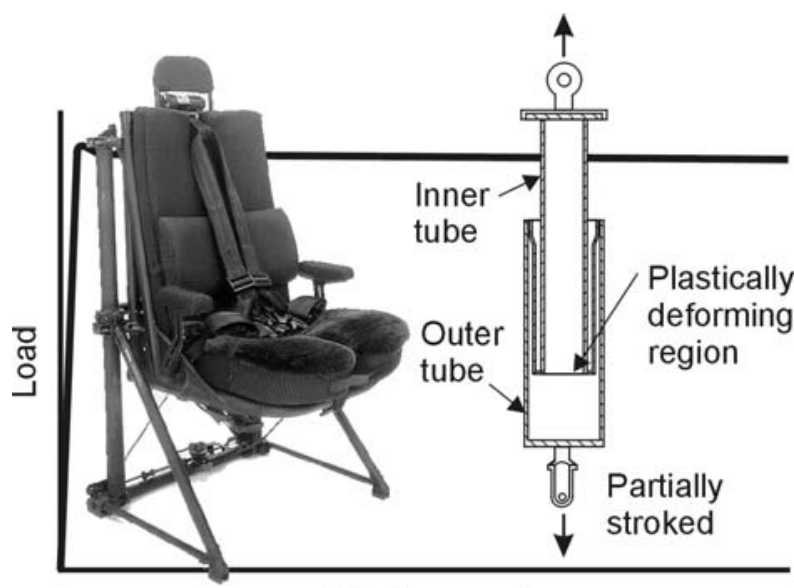

Displacement

Figure 13.

SH-60 Seahawk Unarmored Crewseat, Inversion Tube Energy Absorbers

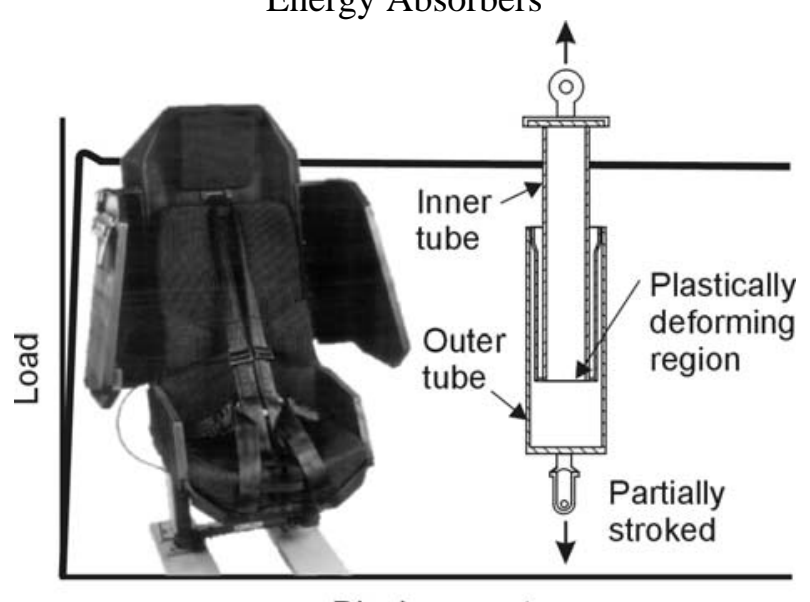

Displacement

Figure 14.

AH-64 and WAH-64 Apache Armored Crewseat, Inversion Tube Energy Absorbers

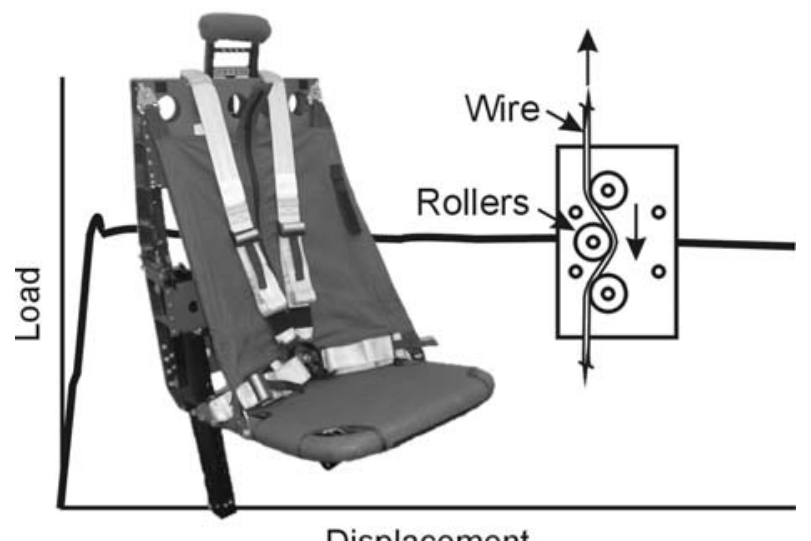

Displacement

Figure 15.

EH101 Foldable Troop Seat, Wire Bender Energy Absorbers

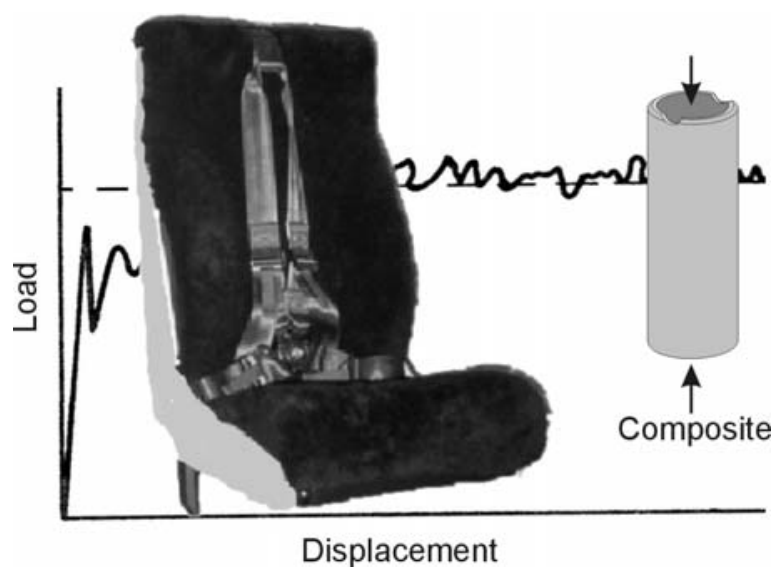

Figure 16.

Bell 230/430 Pilot Seat, Crushable Composite Column Energy Absorbers

Martin Baker Seats: Martin Baker seats use either a tube-through-die or a metal cutting energy absorber approach. The type of device used in each seat is presented in the figure captions. The seats perform in much the same way as described for the Simula seats except the bucket is not necessarily suspended on the energy absorbers. They are located in various places in the seat as shown in the examples, but as with the Simula seats, they support the bucket and occupant. These buckets and stroking mechanisms are attached to the seat frames with shear pins of known shear values. When the loading reaches the known limit load value the pins shear and the seat begins its stroke, resisted by the force required to perform the cutting operation, or by the tube deformation process, depending on the specific seat. Examples of the Martin Baker seats are shown in Figures 17 - 20.

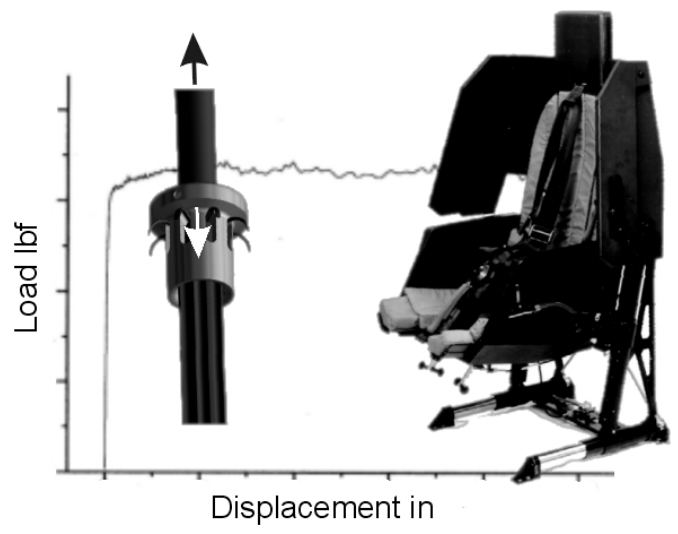

Figure 17.

French/German (Eurocopter)Tiger Armored Crewseat, Metal Cutter Energy Absorbers 


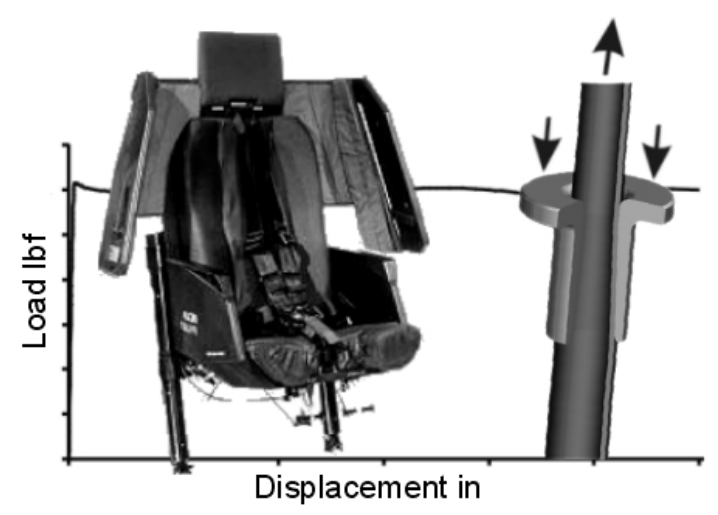

Figure 18.

A129 Italian (Agusta) Armored Crewseat, Tube and Die Energy Absorbers

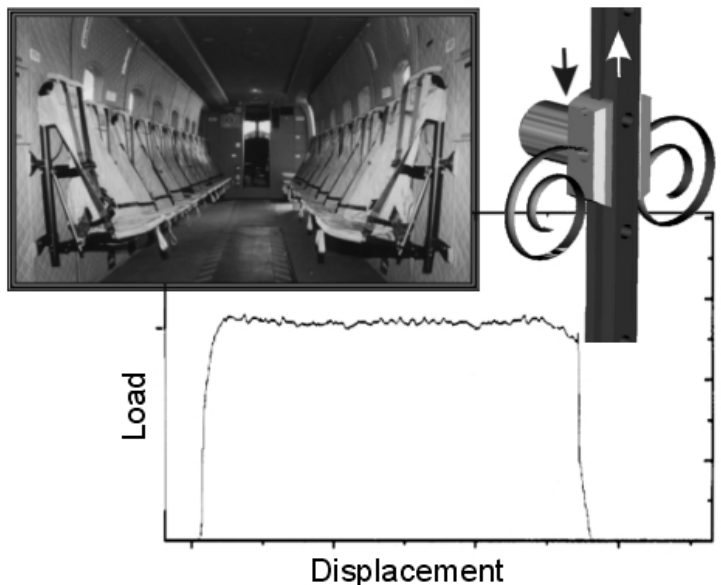

Figure 19.

Utility Seat (CH-53Troop Seat), Metal Cutter Energy Absorbers

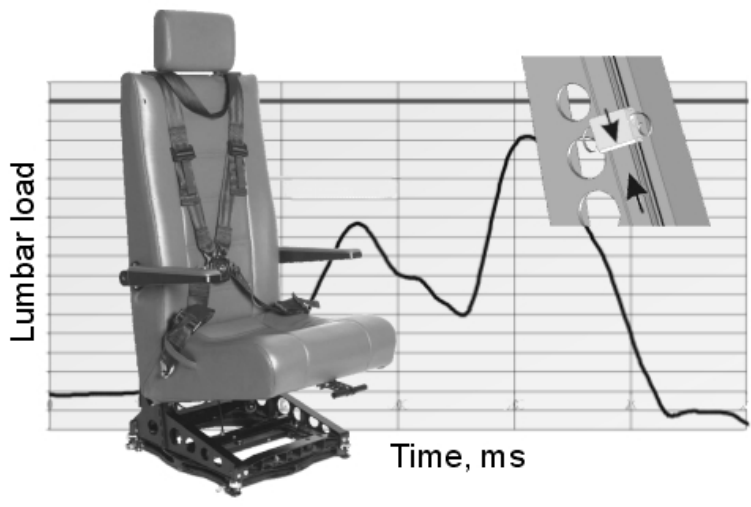

Figure 20.

Integral System, Metal Cutter Energy Absorbers (cuts metal from the seat frame)
Fischer Seats: The Fischer seats all use the bending of a strap, or sheet of metal, as the energy absorbing process. Seat buckets are mounted via slides to right and left legs having rail cross-sections. The energy absorbing process is provided by the progressive bending of the sheet metal straps. The straps are positioned between the slides and the rails. Samples are prepared and tested from every sheet of material used to fabricate energy absorbers to determine the specific strap width needed to provide the appropriate load for each specific seat design. Constant, or fixed, load strap benders were used in all models of Fischer seats certified before 1997. Examples of these seats are shown in Figures 21 and 22.

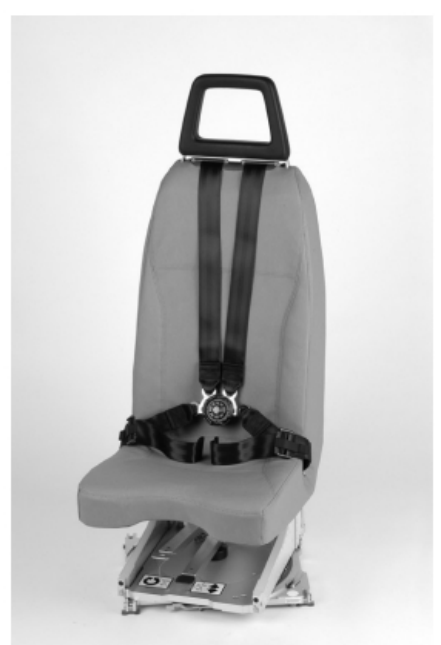

Figure 21.

Bell 230/305 Medical Attendant Seat, Strap Bender Energy Absorbers

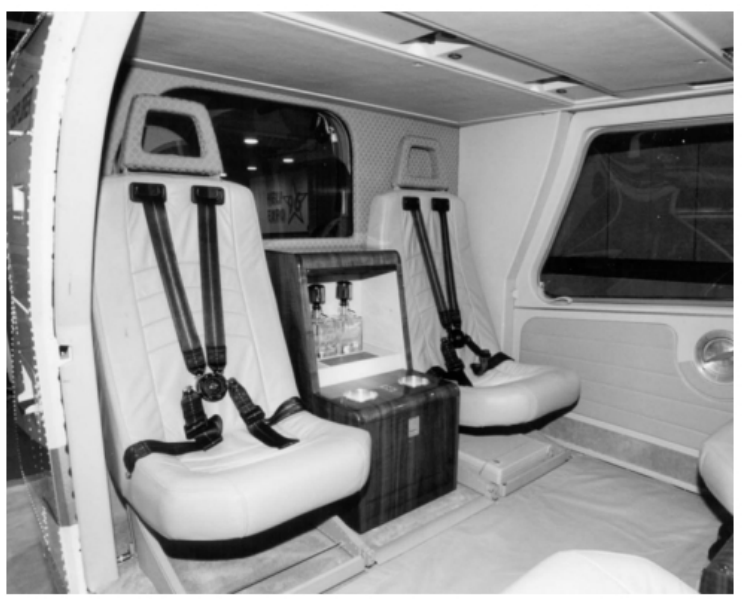

Figure 22.

Bell 236/406 Passenger Seat, Strap Bender Energy Absorbers 
IAI Seats: IAI seats use the second type of tube and die energy absorber mentioned previously. As the seat strokes, tubes are drawn through dies which flattens them, providing a constant load-displacement characteristic. As with the other seats, the bucket is supported by its energy absorbers and is attached to the frame through sliding fittings. The fittings guide the bucket during its stroke. Locking rings installed below the dies prevent the seat from moving upward after the stroke by blocking the reverse motion of the flattened tubes. Examples of these seats are shown in Figures 23 and 24.

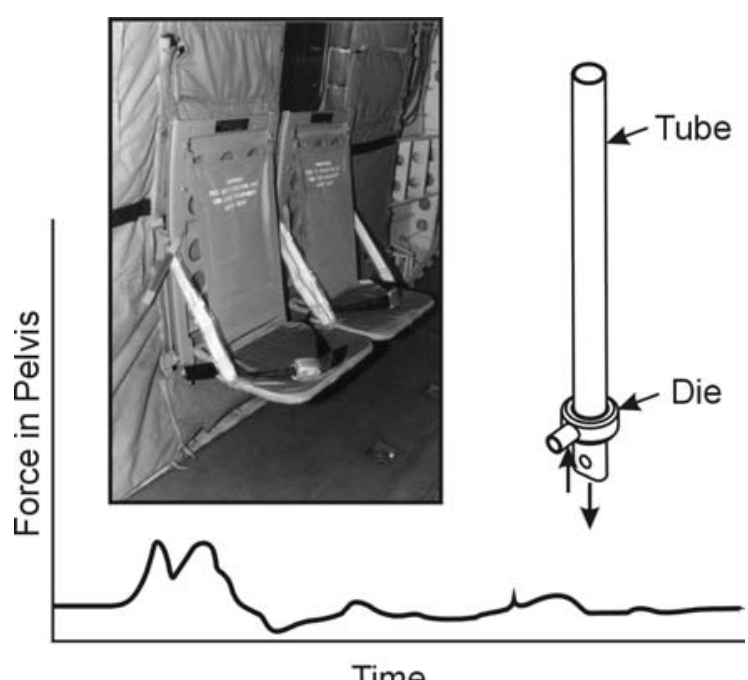

Figure 23.

V-22 Osprey Troop Seat, Tube and Die Energy Absorber

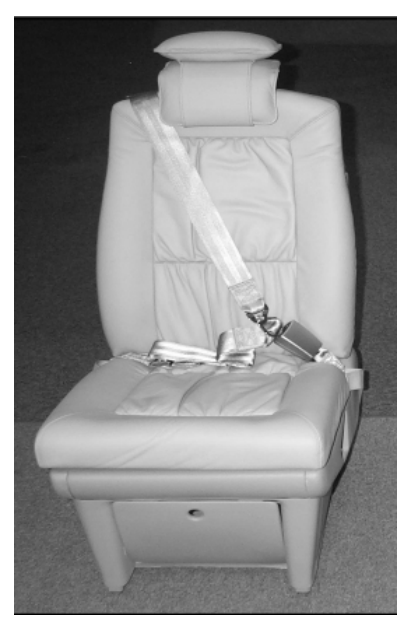

Figure 24.

Luxury Passenger Seat, Tube and Die Energy Absorbers

\section{VARIABLE LOAD ENERGY ABSORBERS}

\section{Selection and Application:}

If the energy absorbing system is to provide only one load setting, that load should be sized for the effective weight of the $50^{\text {th }}$ percentile occupant to ensure a tolerable stroke for the majority of the occupants while not exceeding the stroke limitations of the seats. Since with a fixed load energy absorber, the limit load is sized for the $50^{\text {th }}$ percentile occupant, the $50^{\text {th }}$ percentile occupant will be the only occupant that will be decelerated at the load limit selected as the tolerable limit, the design load limit. The lighter occupants will be decelerated at a higher rate and the heavier occupant will be decelerated a lower rate than will the $50^{\text {th }}$ percentile. Also, even with the recommended minimum12 inches of stroke, heavier occupants in more severe crashes can exhaust the available stroke distance and bottom out. The next logical step in the development of energy absorbing systems was to provide all occupants, regardless of weight, the same level of protection. That capability required an ability to adjust the load to match the weight of the occupant.

For illustration purposes, consider the following example. The standard practice for sizing a fixed single load energy absorbing system is to calculate the effective weight being supported by the energy absorbing system. The effective weight of the $50^{\text {th }}-$ percentile occupant is calculated as follows:

$\mathrm{Wt}_{\text {eff }}=0.80\left(\mathrm{Wt}_{50}+\mathrm{Wt}_{\mathrm{c}}\right)+\mathrm{Wt}_{\mathrm{h}}$

Where $\mathrm{Wt}_{\mathrm{eff}}=$ occupant effective, $\mathrm{lb}$

$\mathrm{Wt}_{50}=$ occupant nude weight, $\mathrm{lb}$

$\mathrm{Wt}_{\mathrm{c}}=$ weight of clothes, $\mathrm{lb}$

$\mathrm{Wt}_{\mathrm{h}}=$ weight of helmet, $\mathrm{lb}$

Then for the $50^{\text {th }}$-percentile army pilot,

$$
\mathrm{Wt}_{\mathrm{eff}}=0.80(170.5+3.1)+3.4
$$$$
\mathrm{Wt}_{\mathrm{eff}}=142.3 \mathrm{lb}
$$

Using the same approach to determine the effective weights for the $95^{\text {th }}$ - and $5^{\text {th }}$ - percentile male aviators yields 175.2 and $112.6 \mathrm{lb}$ respectively. Assuming a 60 pound movable seat weight, the total effective weights that the load limiting system must be designed for are:

$5^{\text {th }}$ - percentile: $172.6 \mathrm{lb}$

$50^{\text {th }}$-percentile: $202.3 \mathrm{lb}$ 
$95^{\text {th }}$-percentile: $235.2 \mathrm{lb}$.

Disregarding friction, rate sensitivity, etc., the $50^{\text {th }}$ percentile limit load $\left(\mathrm{L}_{\mathrm{L}}\right)$ is calculated as follows:

$\mathrm{L}_{\mathrm{L}}=\mathrm{G}_{\mathrm{L}} \mathrm{Wt}_{\mathrm{eff}}=(14.5)(202.3)=2,933 \mathrm{lb}$

With a fixed load energy absorber, the resultant load factors for the $95^{\text {th }}$ - and $5^{\text {th }}$ - percentile aviators are:

$$
\begin{aligned}
& \mathrm{G}_{\mathrm{L} 95 \mathrm{th}^{-}}=2,933 / 235.2=12.6 \\
& \mathrm{G}_{\mathrm{L} 5 \mathrm{th}}=2,933 / 172.6=17.0
\end{aligned}
$$

To provide the same limit load for the all occupants in the size range of its users, it was desirable to have energy absorbers that could be adjusted to provide the appropriate load for each occupant regardless of size/weight. This type of energy absorber was called the variable load energy absorber and using the weight range of the $5^{\text {th }}$ to the $95^{\text {th }}$ percentile male aviator (This was the specified occupant size range at the time these seats were first introduced.), the loads at the design extremes were:

$$
\begin{aligned}
& \mathrm{L}_{\mathrm{L}}=(14.5)(235.2)=3,410 \mathrm{lb} \\
& \mathrm{L}_{\mathrm{L}}=(14.5)(172.6)=2,503 \mathrm{lb} .
\end{aligned}
$$

The desired characteristics of a constant but variable load energy absorber (VLEA) are illustrated in Figure 25. With this infinitely variable system, the loaddisplacement characteristic can be adjusted to any value between the extremes shown. The deceleration levels can be maintained within acceptable limits (if the design crash pulse is not exceeded) for the full range of occupant weights. With the fixed limit load set for the $50^{\text {th }}$ percentile occupant weight, the calculated load factors were 12.5 for the $95^{\text {th }}$ and 17 for the 5th percentile male occupant weights. This produced a negative variation of $2.0 \mathrm{G}$ for the heavy occupant and a positive variation of $2.5 \mathrm{G}$ for the lighter occupant from the design factor of $14.5 \mathrm{G}$. These variations become even larger with the addition of female pilots. It can be seen that an infinitely adjustable mechanism reduces the variation to zero giving all occupants the same protection. and establishing the need for variable load energy absorbers.

Simula conducted initial work on such a system under a US Navy contract $[18,19]$ and as a result, variable load energy absorbing systems were developed and installed on several aircraft. Examples of aircraft equipped with seats having VLEA energy absorbers 


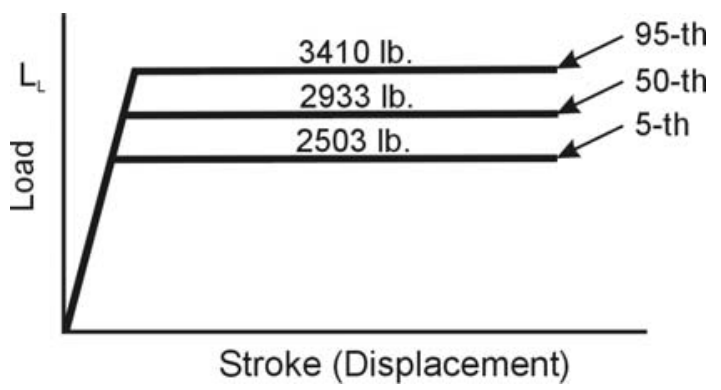

Figure 25.

\section{Variable Load Energy Absorber Adjustment Range}

include the $\mathrm{V}-22$, Japanese $\mathrm{OH}-1 / \mathrm{OH}-\mathrm{X}$ (two stage rather than infinite), UH-1Y, AH-1Z, EH101 (armored and unarmored), $\mathrm{CH}-53, \mathrm{SH}-3$, and RAH-66 helicopters. All of these seats used inversion tube type energy absorbers except the $\mathrm{V}-22$ and the $\mathrm{OH}-1 / \mathrm{OH}-\mathrm{X}$, which used wire benders.

With wire bender energy absorbers the force required to draw the wire through the rollers is a function of the relative location of the rollers. Therefore, variable load energy absorbers were developed to allow load adjustment by selectively changing the location of the center roller. Figure 26 shows the V-22 seat, and schematically, the adjustment of the center roller. The manual control knob used to adjust the load was located on the housing that contained the coil of wire that is drawn through the rollers as the seat strokes in a crash. The knob was indexed and calibrated to enable the occupant to select the setting that would provide the optimum load for his/her weight before sitting down in the seat.
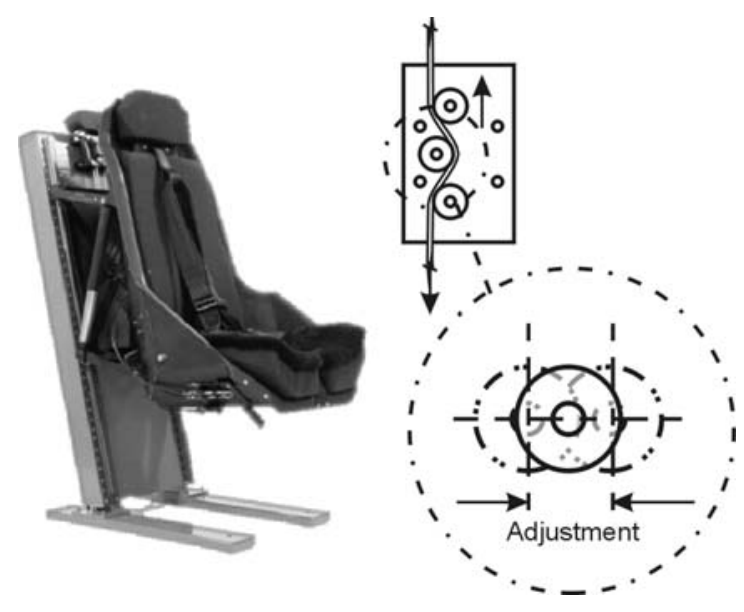

Figure 26.

V-22 Osprey Armored Crewseat, Variable Load Energy Absorbers (VLEA), Wire Bender
The Japanese $\mathrm{OH}-\mathrm{X}$ also used variable load energy absorbers, but they were designed to provide only two separate load settings. The $\mathrm{OH}-\mathrm{X}$ is shown in Figure 27.

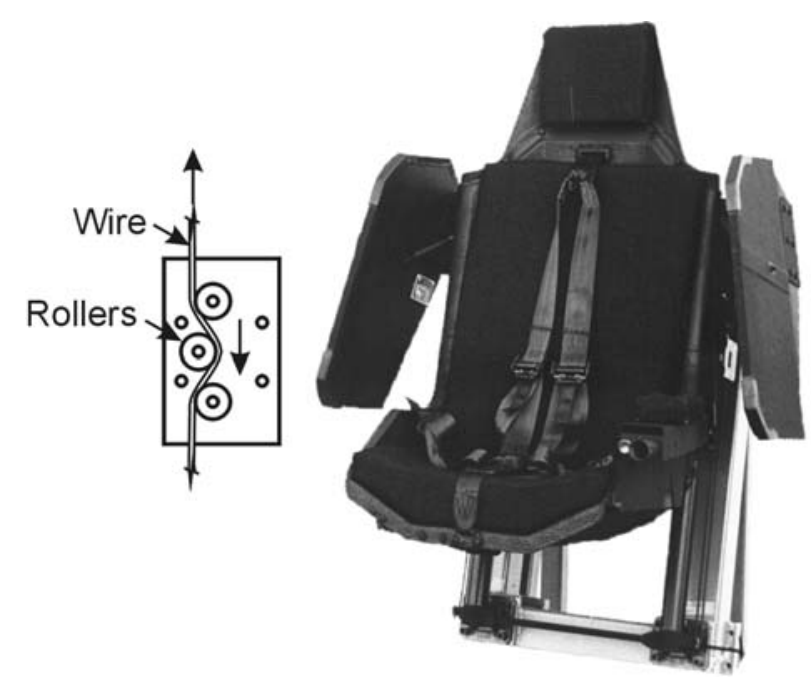

Figure 27.

Japanese OH-X, Armored Crewseat, Variable Load Energy Absorbers (Two Stage VLEA), Wire Bender

For seats equipped with variable load inversion tube energy absorbers, manual adjustment was made in the same way as with the wire bender, by an indexed and calibrated control knob. However, the knob was located on the side of the bucket in a position that allowed the adjustment to be made by a seated occupant. The adjustment itself was made by a mechanism that added load to the basic load produced by inverting the inversion tube. The inversion tube was designed to invert at or near the lowest load required (lightest occupant). The additional load for the heavier occupants was created by increasing the depth that balls, placed around the inside periphery of the inverted section of the inversion tube, deformed the tube as it was inverted and drawn past the balls. The radial position of the balls was established by the location of a cam upon which the balls were seated. Rotation of the control knob in one direction moved the cam allowing the balls to displace to a lesser radius producing a shallower groove in the inverted portion of the tube and producing a lower load. Moving the balls to a greater radius produced deeper grooves and a 
higher load. The depth of the grooves of course was correlated to the rotation of the knob and calibrated and indexed. Examples of these seats are shown in Figures 28 through 30.
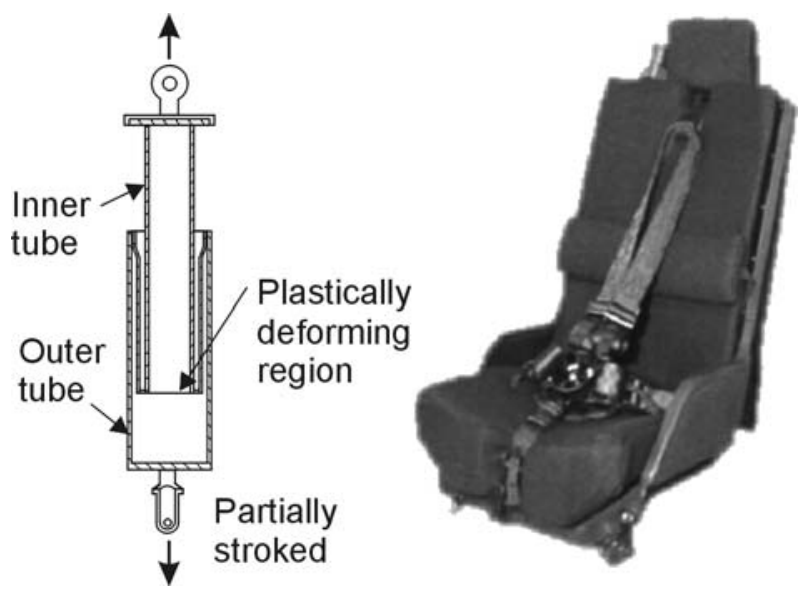

Figure 28.

AH-1Z Armored Crewseat, Variable Load Energy Absorbers (VLEA), Inversion Tube
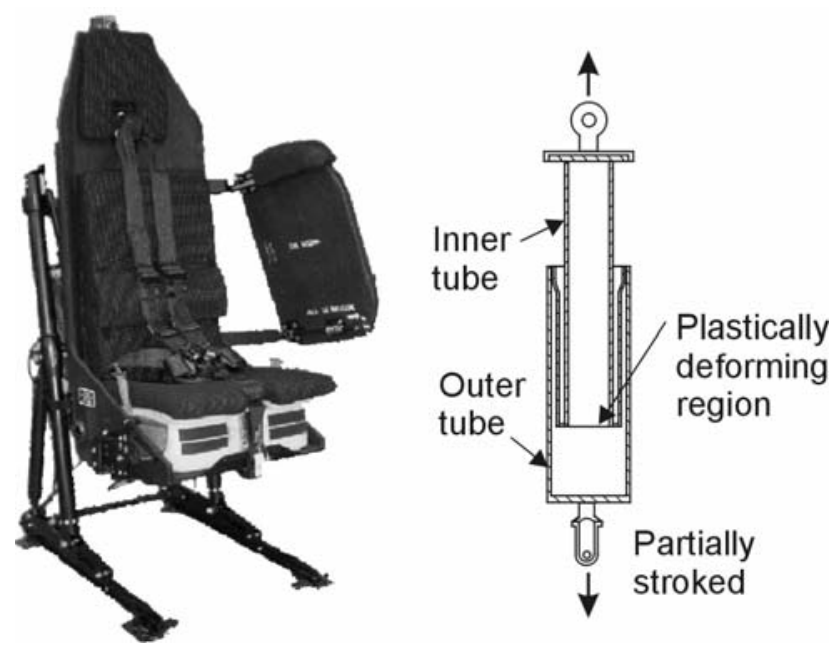

Figure 29.

EH101 (RAF \& MMI) Armored Crewseat, Variable Load Energy Absorbers (VLEA), Inversion Tube
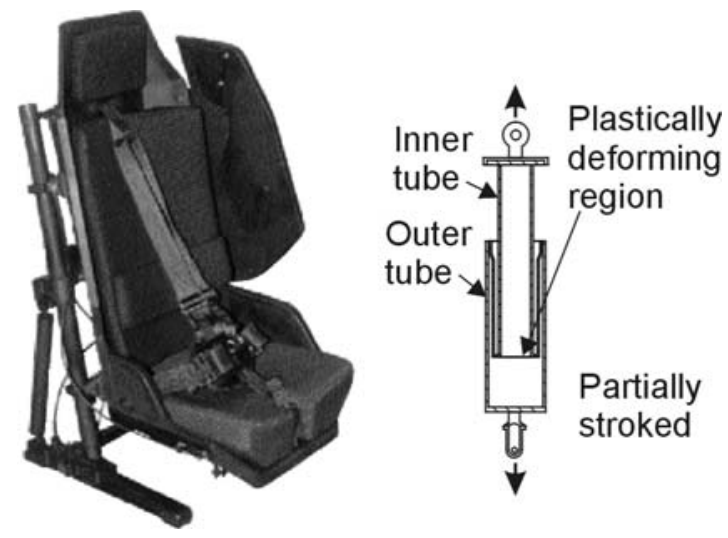

Figure 30.

UH-1Y Armored Crewseat, Variable Load Energy Absorbers (VLEA), Inversion Tube

\section{FIXED LOAD-DEFLECTION PROFILE ENERGY ABSORBERS (VPEA)}

\section{Selection and Application}

In 1970, Carr and Phillips, working under a contract with the Naval Air Development Center (NADC), released the results of a study that indicated that it might be possible to realize a more efficient stroke than that provided by a constant load energy absorber [20]. They suggested that a load-displacement profile that was not constant, but designed to take advantage of the dynamic response of the human body, might produce improved efficiency. A "notched" load-stroke profile was suggested that would compress the "springs" in the human body more quickly by imposing a high initial load spike. It would then lower the load rapidly to minimize the overshoot as the body "springs" loaded up and bottomed thereby limiting the maximum load imposed on the occupant's spine. The energy absorber load would then be increased again more slowly to a plateau that could be sustained with the body "springs" loaded and compressed for the rest of the stroke. This type of load-displacement profile would allow the body to be decelerated at a higher average load by minimizing the overshoot that is the typical response of such a spring-mass system undergoing a rapid application of loading. Since the maximum load in the spine typically results from overshoot, minimizing the overshoot, allowed the average load to be raised while keeping the spine load within human tolerance limits. 
A somewhat simplified explanation of this phenomena is presented graphically below, Figure 31. A more detailed discussion of the occupant response to this type of loading is presented in pages 59 through 64 of Reference 5.

(a) Occupant response (FLEA)

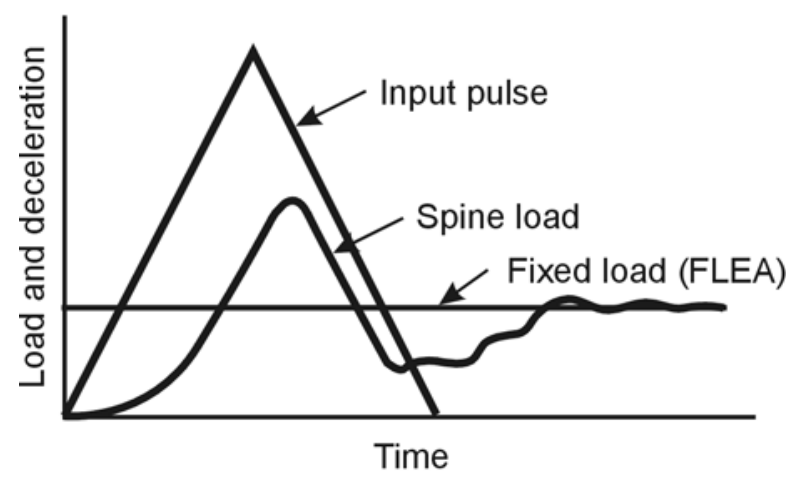

(b) Occupant response (FPEA)

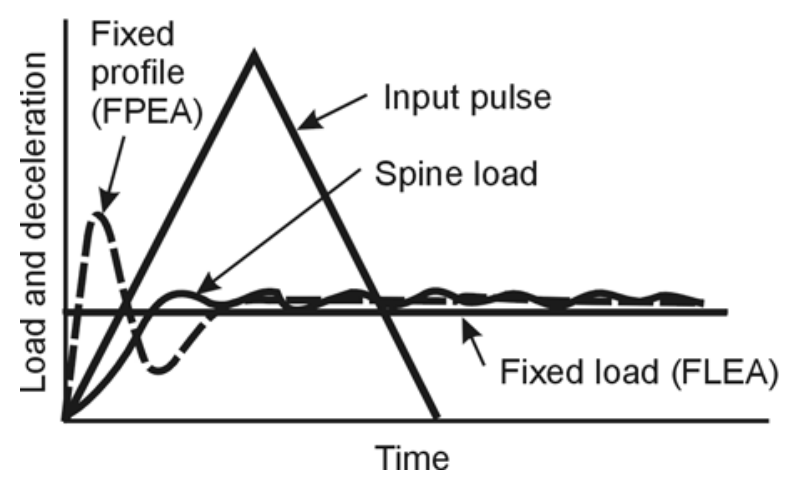

Figure 31.

Conceptual Explanation of the Fixed Profile Energy Absorption Process.

If this approach could be implemented successfully, which means in phase with the response of the body, it could reduce the stroke required to decelerate the occupant while limiting loads to the humanly tolerable level. To the author's knowledge, two seat suppliers have incorporated the fixed profile energy absorber (FPEA) into their products, Fischer and Skyline. A combination of these approaches has also been studied by Simula to provide a spectrum of improvements, including variability, and is summarized under Advanced Systems in this paper.
Fischer: Fischer has endeavored to increase the efficiency of their energy absorbing seats over time, and has adopted the technique provided by the fixed profile, or notched load-stroke energy absorber characteristic. All Fischer seats developed/certified after 1997 incorporate the fixed profile energy absorber design. Fischer has monitored its progress in reducing stroke as a function of seat model certification and the results are presented in the bar graph of Figure 32.

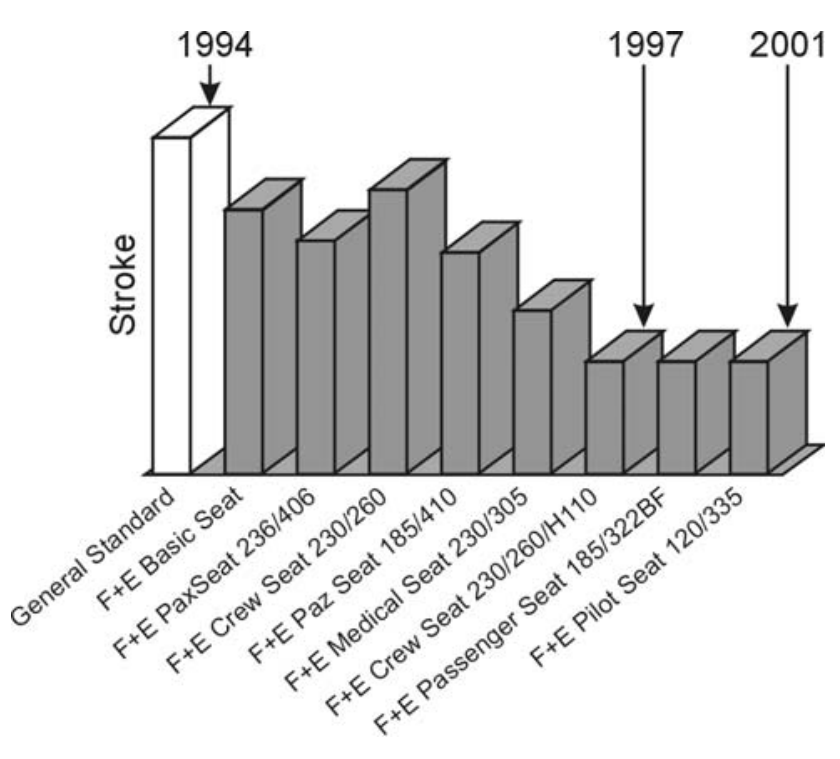

Figure 32.

Seat Stroke as a Function of Seat Model Certification

The figure shows that through experimentation and modification of the stroke-displacement, stroke-time characteristics of the energy absorbing system, seat strokes have been reduced from slightly over six inches to a little over two inches while limiting the load measured in the spine of the $50^{\text {th }}$ percentile anthropomorphic test dummies to magnitudes below the $1500 \mathrm{lb}$ limit (civil helicopter requirement). As explained in a previous section of this paper, the Fischer seats use a strap bender energy absorber. The load-stroke profile is provided by varying the strap width along its length. Samples from every sheet of material used are prepared and tested to determine the specific strap width needed to provide the proper loaddisplacement profile for the application. Examples of the Fischer seats using the fixed profile energy absorber concept are shown in Figures 33 and 34. 


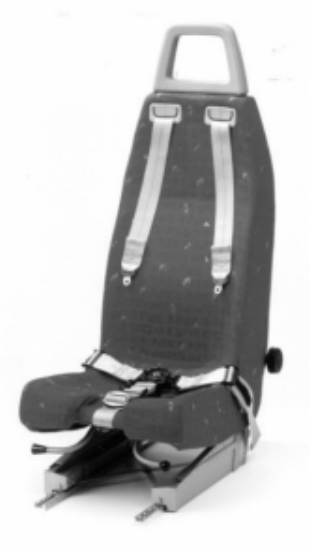

Figure 33.

Bell 230/260 Pilot Seat, Strap Bender Energy

Absorbers, FPEA

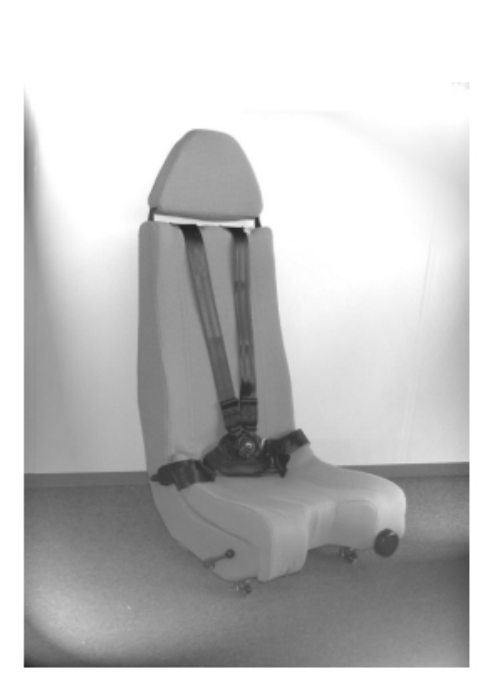

Figure 34.

Bell 236/406 Passenger Seat, Strap Bender Energy Absorbers, FPEA

Skyline: Skyline has developed energy absorbing troop seats for use in the UH-1Y and in the U.S. Army Airborne Command and Control System (A2C2S) operator seats. These seats use a different approach to providing the fixed profile energy absorbing stroke. A wire bender is used but the design is somewhat modified in that the wire has a rectangular, rather than round, cross section. The wire is routed around rollers approximately in the usual configuration. The wire has a varying cross section to provide the variation in load with stroke. The load-stroke profile used is shown and compared with the constant load characteristic in Figure 35. The energy absorber used by Skyline has been patented (US Patent Number 6,394,393). Examples of the Skyline seats are shown in Figures 36 and 37.

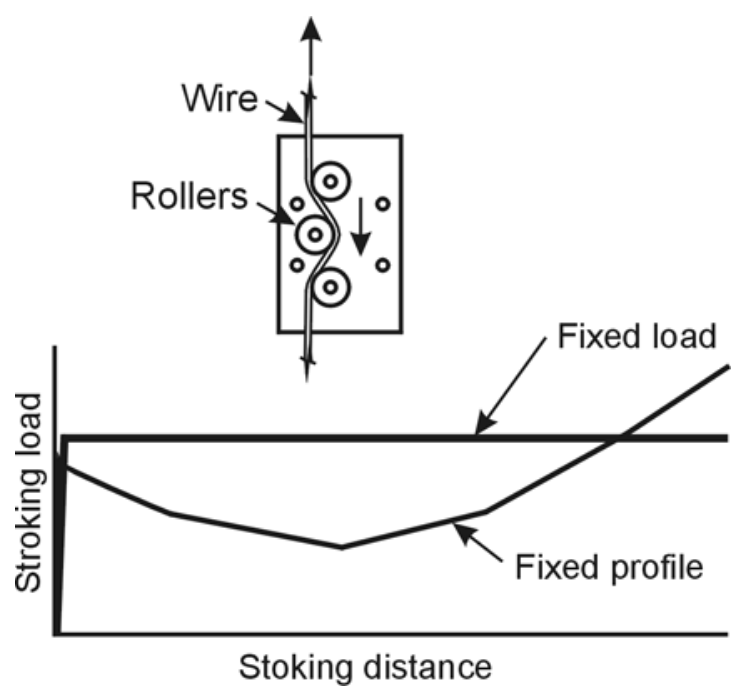

Figure 35.

Load-Stroke Profile Compared with Constant Load, Wire Bender

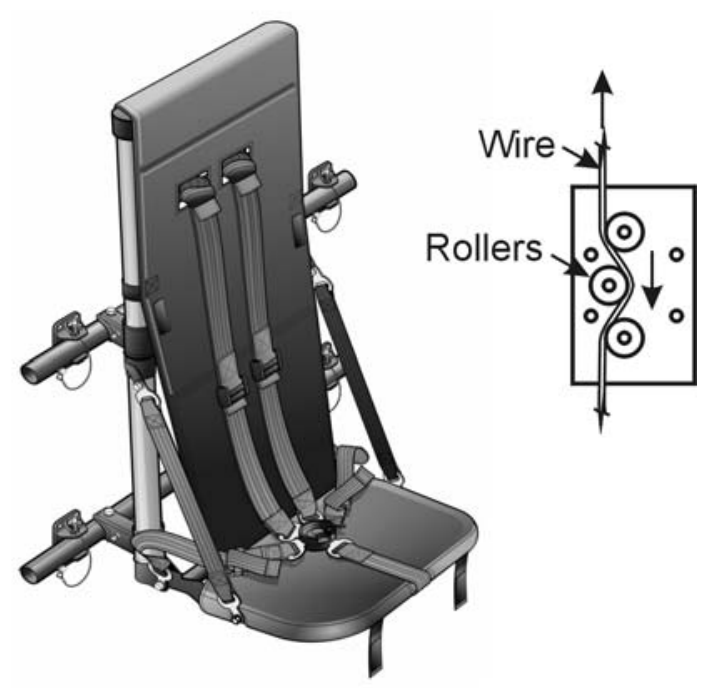

Figure 36.

UH-1Y Troop Seat, Wire Bender, FPEA 

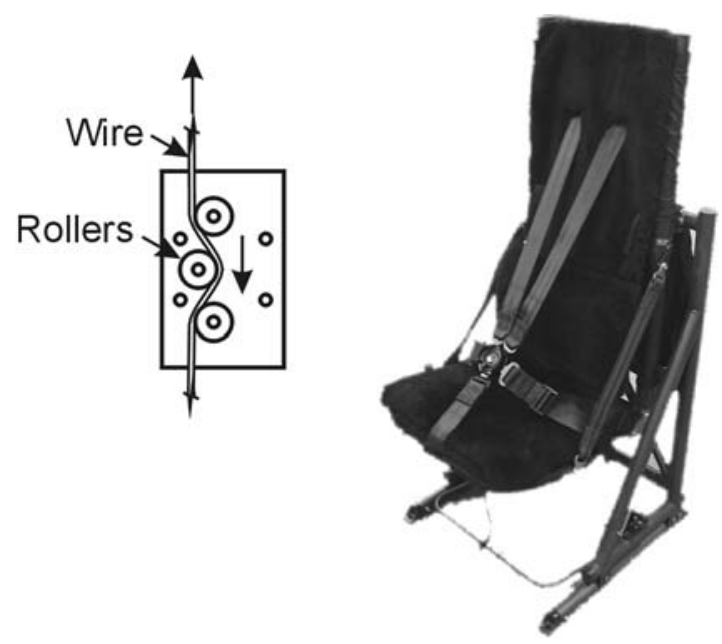

Figure. 37.

A2C2S Operator Seat, Wire Bender, FPEA

\section{ADVANCED SYSTEMS}

\section{Program Objectives}

In the period between 1992 and 1997 Simula, under contract to the United States Navy, conducted a program to improve the efficiency and the reliability of energy absorbing seating systems [22]. The program was directed towards creating the "third generation" of energy absorber technology for helicopters seats. The first generation of energy absorbing seats used fixed load energy absorbers to limit the compressive force in the occupant's spine during a crash. The limit loads of the devices were sized for the mid- range of occupants, the $50^{\text {th }}$ percentile. The second generation of energy absorbers was developed with a provision for manually adjusting the stroking force so that the entire range of occupant sizes using the seat would receive equal protection during a crash. As part of the second generation, two seat suppliers, Fischer and Skyline, adopted the fixed profile (FPEA) approach to improve the efficiency of the process. The goal of the third generation program was to develop systems that could provide the maximum efficiency to all sizes of occupants and remove the possibility of human error during use of the systems. It is worth noting here that in the early 1980's Simula conducted a US Navysponsored program to develop an automatically controlled variable-load energy absorber for crashworthy seat application [23]. That program, together with this more recent one, are expressions of the Navy's longtime commitment to providing its aviators with the best possible crash protection.
To accomplish the overall goal, one objective of the next generation energy absorber program was to eliminate the need for manual adjustment thus eliminating the possibility for human error by the seat occupant in selecting the appropriate load for his/her weight. To accomplish this objective, the prototype Weighing and Adjusting Module, WAM, was developed. A prototype was assembled and tested and successfully determined the weight of each occupant and correctly adjusted the energy absorber in static situations. The automatic adjusting feature was developed to be applicable to both the existing manually adjusted energy absorbers, and to the new variable profile energy absorbers (VPEA). Variable profile, as used here, refers to the ability to provide force, or load, profiles matched to the occupant's weight. The automated adjusting system performed successfully when tested, but requires additional development, production design, and qualification on a specific seat system to be considered a system ready for fielding. Once these tasks are accomplished, the automated adjusting system offers the ultimate in energy absorber system design. It matches the energy absorber characteristics to the occupant regardless of weight through use of the weighing and adjusting module, it uses the variable profile load-deflection characteristics to ensure correct EA adjustment, and it eliminates the possibility of human error. The system developed offers a degree of complexity however, that may discourage its adoption.

The other objective for the next generation energy absorber development effort was to deliver the same level of spinal protection in less seat stroking distance, thus enabling more efficient use of limited aircraft space. An energy absorber in which the force follows a predetermined profile (FPEA) as the seat strokes was developed in the program. The profile was established based on the response of the human body to a deceleration impulse. During the program not only was the feasibility of the profile energy absorber concept demonstrated, but also that the profile can be designed to take advantage of the efficiency gain to improve different aspects of seat performance. Two quite different energy absorbers were developed. One set of EA profiles was selected to minimize stroking distance for the heaviest occupants, while another set was developed to optimize lumbar protection across the entire range of occupants. 
The program developed two distinctly different solutions or products. One of the new energy absorbers responded directly to the technical objective of this program, while the other was a potential retrofit for existing fixed-load energy absorbing seats to improve their efficiency.

\section{Variable Profile Energy Absorber (VPEA)}

In the first phase of this program, a variable profile energy absorber concept (VPEA) was developed to reduce the seat stroke required for the mid-weight and heavy occupants by 25 percent or more in the standard vertical test. Rather than the constant, or fixed, loadprofile that was used in earlier generation energy absorbers, the VPEA had the more complex loadstroke profile previously discussed in this document. The profile was characterized by a sharp initial peak, followed by a low load level, "notch", which controls the peak lumbar load caused by dynamic overshoot of the upper torso. The load then rose to the "hold load" near the injury tolerance limit of the spine. This profile was achieved on a seat by extensive modification of an existing adjustable inversion tube energy absorber (VLEA). Profiles were developed for the various occupant weights. The adjustment range of the new energy absorber was sufficient to accommodate all aviators in the weight range from the $5^{\text {th }}$-percentile female to the $95^{\text {th }}$-percentile male and still limit the peak lumbar load to levels below the injury tolerance limit.

Figure 38 shows the profiles developed for the three model occupants. The initial peak load varied as a different function of occupant weight than the "hold load". The relationship between the initial peak load and the hold load was designed into the hardware. The WAM system processor converted weight sensor readings to angular shaft positions and set the entire profile with one adjustment.

\section{VPEA Mechanical Design Details}

A cross-section of the prototype VPEA is shown in Figure 39. The three load-control components are the variable initial load spike shear connection, the aluminum honeycomb column that provides the notch load and the inversion tube with indentation mechanism that provides the variable hold load.

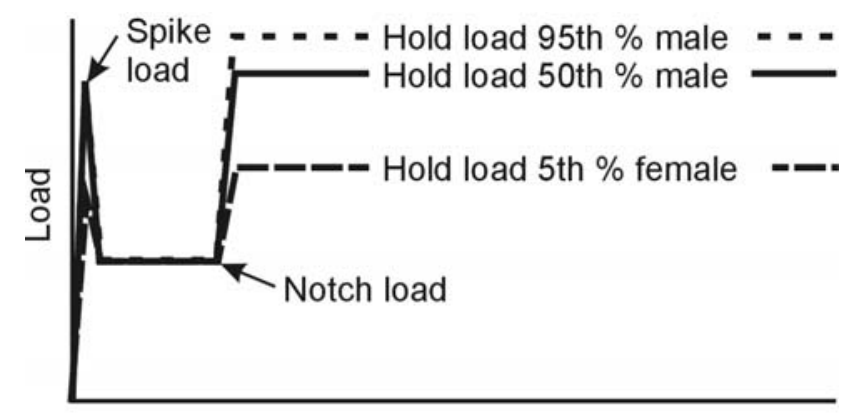

Displacement

Figure 38.

Variable Profile Energy Absorber (VPEA) LoadStroke Characteristics

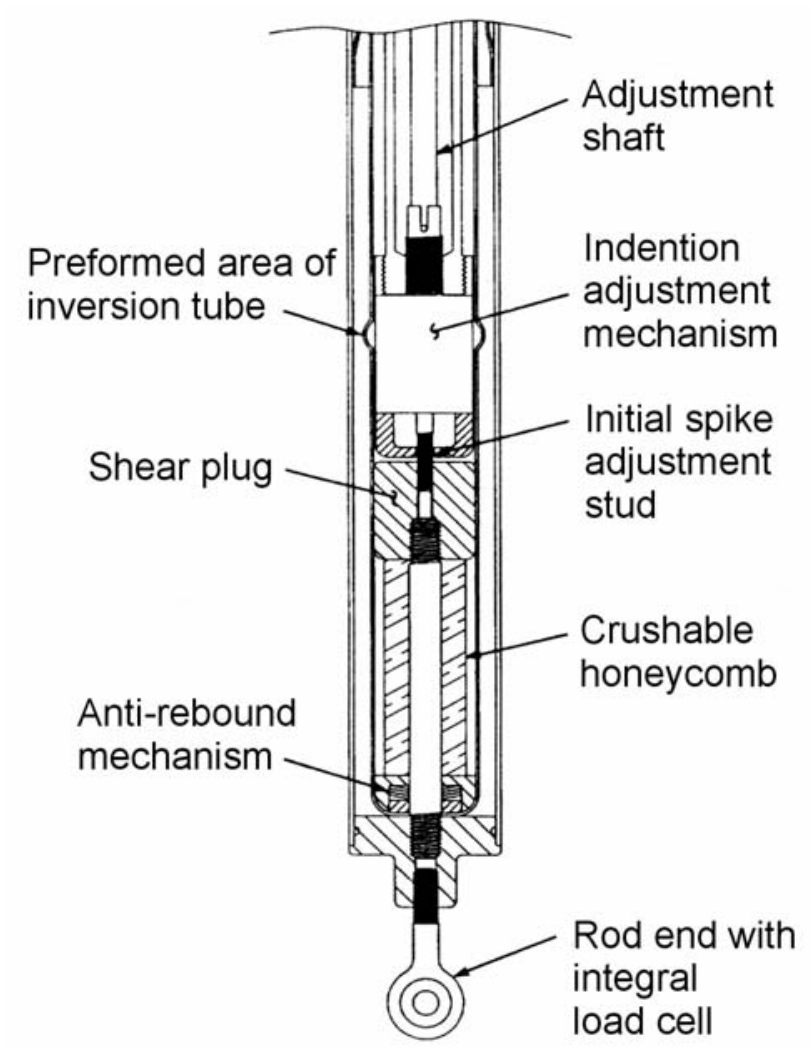

Figure 39.

Variable Profile Energy Absorber (VPEA)

Cross-Section

The energy absorber was dynamically tested for light, medium, and heavy occupants in the pure vertical case, and the improved stroking performance as well as the lumbar protection, was confirmed. This new energy absorber was then tested in five different crash 
scenarios with the median weight occupant and performed better than the fixed-load energy absorber (FLEA) in three of the five conditions and comparably in the other two. In the second phase of this program, the performance of this energy absorber was modified to deliver lower lumbar loads for all occupants, especially in the nose down events and events with high onset rates. Thus, the efficiency gains of the VPEA were reallocated from stroke reduction to peak lumbar load reduction to provide the desired protection across the occupant weight range.

\section{Fixed Profile Energy Absorber (FPEA)}

In a second phase of work, a design incorporating a fixed profile was developed and dynamically tested. The FPEA was designed to provide a notched-load profile as shown in Figure 40. This load-displacement relationship was selected to minimize the dynamic stroking distance for the $95^{\text {th }}$-percentile male while still meeting the lumbar tolerance criteria for a 50thpercentile female, which, for this program, was selected as the lowest weight extreme.

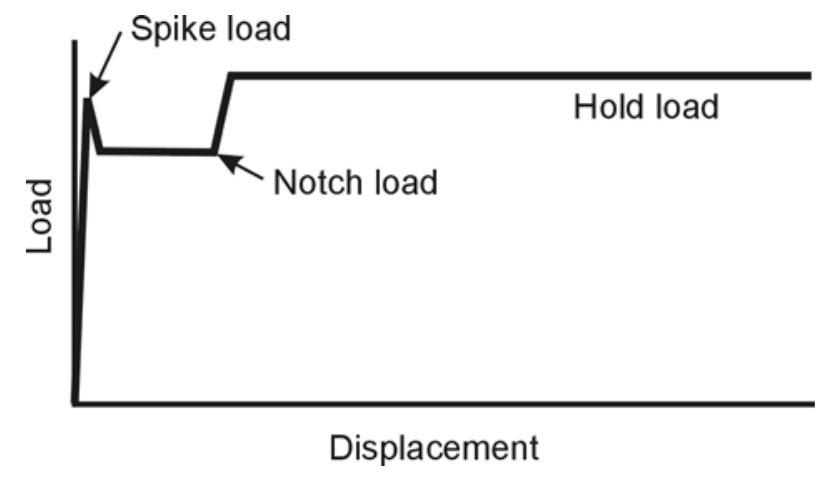

Figure 40.

Fixed Profile Energy Absorber (FPEA) Load-Stroke Characteristic

Components of the FPEA were the shear plug, the notch load inversion tube and the hold load inversion tube. At the onset of loading, the shear rod resisted the displacement providing the initial loading spike as shown in Figure 41-a. When the shear rod was released the load dropped to the value required to stroke the inversion tube that provided the notch load, Figure 41-b. Once the notch load inversion tube bottomed out, the load rose to the hold load and began stroking the second inversion tube provided for that purpose (Figure 41-c).

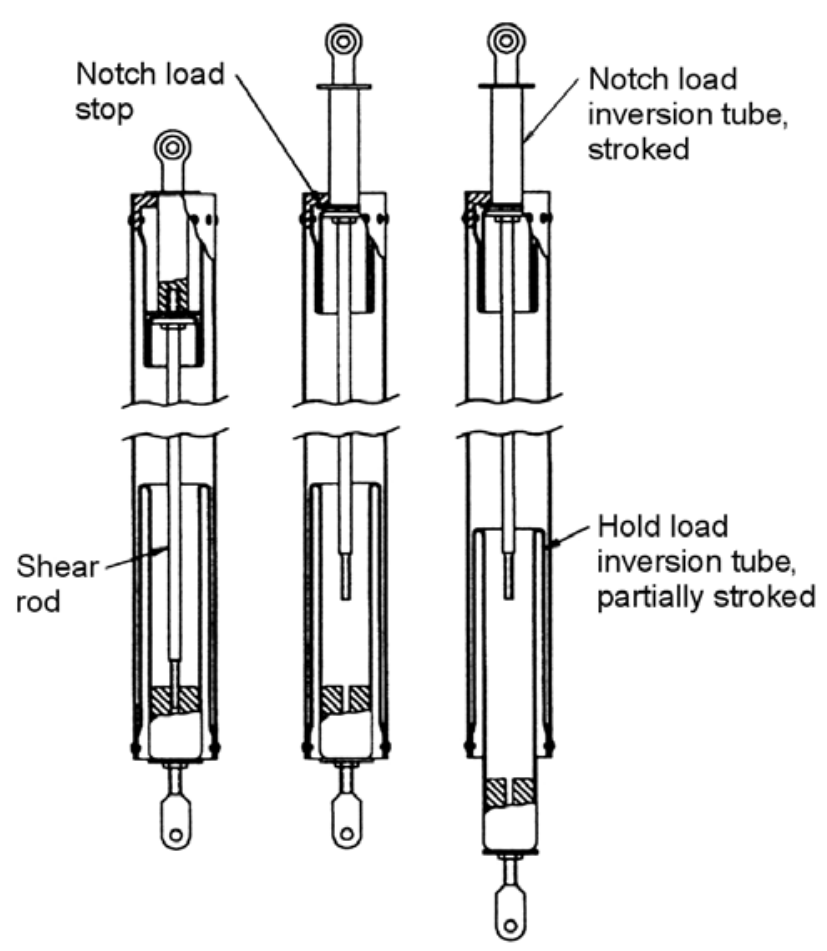

(a) (b)

(c)

Figure 41.

Fixed Profile Energy Absorber (FPEA) Load-Stroke Characteristic

The phase one design successfully reduced the stroke required for the median and heavy occupants, while keeping the peak lumbar loads below the injury tolerance limits. However, for the small occupant, the injury tolerance limit was exceeded. In the second phase, Simula revised the profile on this device to meet the injury tolerance of the lightest occupant while increasing the stroke for the heaviest occupant up to, but not beyond, the stroke for the current fixed-load energy absorber. This energy absorber concept has the potential to become a retrofit upgrade for seats currently using fixed-load energy absorbers. With this retrofit, seats would better be able to accommodate and protect the lightest aviators with no sacrifice in performance for the heavier aviators and without increased complexity.

Conduct of this program resulted in the creation of improved energy absorption technology that can provide new seat design options for those responsible 
for the performance requirements of crashworthy helicopter seats.

\section{DISCUSSION OF RESULTS}

\section{Overall Performance of Crashworthy Seats}

The overall performance record for crashworthy seats is rewarding. The U.S. Army Black Hawk helicopter was the first helicopter designed and built to modern crashworthiness standards. Dr. Shanahan reported on the crash performance of the Black Hawk at the referenced AGARD meeting [24]. Specific comments about the performance of the two seats that have been used in the aircraft, Simula's and ARA's, follow. With regard to the Simula seat Shanahan stated, "This seat has provided superior performance in Black Hawk crashes up to $18.3 \mathrm{~m} / \mathrm{sec}$ (60ft/sec) vertical impact velocity. The seat has been consistently retained in place in all potentially survivable crashes. In the crash shown in Figure 9 not included in this paper\} seat retention and its energy attenuating capability were determined to be the primary contributors to the survival of both pilots when most of the surrounding structure had disappeared. Several similar UH-60 crashes have proven the importance of providing seat retention capability in excess of estimated human tolerance limits." With regard to the ARA seat, a few deficiencies were mentioned, but the overall observations for this seat were also positive. They were summarized as "In spite of these deficiencies, this seat has performed well in the Black Hawk crash environment". Dr. Shanahan goes on to say that "With recent advances in energy attenuating seat technology, several U.S. Army agencies are advocating changing applicable specifications to provide for a new generation seat restricted to a uniaxial stroke and equipped with variable load energy attenuators”.

It is apparent that the adoption of crashworthy energy absorbing seats in helicopters has been fruitful. Their record, at least in the military application, has been positive. They have successfully performed their mission of minimizing the risk of fatality, disability, and serious injury in survivable crash scenarios and in some cases, beyond.

\section{Civil Certification Requirements}

There are areas of concern with the civil certification process. The certification process for civil helicopters requires testing with only a $50^{\text {th }}$ percentile anthropomorphic dummy. Testing with the other sized dummies is not required, and consequently, to the author's knowledge, has not been done for civil helicopter seats. From an operator's viewpoint it is desirable to have a short stroke. Less space must be conserved in the cockpit and cabin to allow room for seat stroke in the event of a crash. Further, it is desirable because if the seat can be certified with a very short stroke, personal items, such as briefcases, can be placed underneath the seat. Since the needed stroke has been assessed during certification testing using only the $50^{\text {th }}$ percentile dummy, it is apparent that the heavier occupants will bottom out in the more severe crashes and risk severe injury. Consequently it would appear that certification testing using only the $50^{\text {th }}$ percentile dummy is inadequate to assure all occupants protection even in the prescribed crash environment.

The desirability of certified seats with the shortest possible stroke also extends the concern cited in the preceding paragraph. It will encourage seat suppliers to be innovative and to develop seats with energy absorbing systems that require very short strokes. One way to accomplish this is by using the fixed profile energy absorber. The existing certification process can result in systems being tuned for the response of the available $50^{\text {th }}$ percentile anthropomorphic test dummies. This practice could be dangerous if the full spectrum of occupant weights is not considered. Fixed profile energy absorbing systems are very sensitive to the location of the notch in the load-displacement characteristic, and possibly the magnitudes of the loads in the profiles.

In the early 1970's Reilly tried to incorporate the "notched", or fixed profile wire bender energy absorber in the troop seat being developed for the Black Hawk helicopter [21]. Wire of varying diameter was investigated in order to produce the notched forcedisplacement curve as recommended by Carr and Phillips [20]. It was concluded in this study that the notched force-deflection curve was not suitable for lightweight troop seats due to the sensitivity of the system response to location of the notch in the load vs. displacement characteristic. Reilly concluded that a fixed location for the notch was not compatible with the various dynamic response phasing differences resulting from the wide range of troop and equipment weights. The trapezoidal force-displacement curve produced by the constant, or fixed, limit-load device, although not as efficient theoretically and ideally as the 
notched curve for a specific dynamic condition, appeared to be more tolerant of the wide range of seat occupant weights.

To the knowledge of this author, the effects of occupant size on response and its affect on the phasing of the peaks and valleys of the load-displacement profile, as experienced by Reilly, have not been assessed in civil seats. If these effects have not been assessed, and the system response is as sensitive as Reilly found, seats using the fixed profile energy absorbing system may not provide the desired protection to other than $50^{\text {th }}$ percentile male occupants. It is also noteworthy that others working to define a profile that will adequately protect a range of occupant weights have settled on much different shaped profiles than that suggested by Carr and Phillips. For example, note the profile developed by Skyline, Figure 35, where a wide range of dummy sizes were used in the qualification process. Because civil seats are light in weight, not carrying armor and designed to meet the civil requirements, they may be more sensitive than would a military seat designed to more severe requirements and in some cases carrying armor. The additional weight of the military seats may make them less sensitive to the specific profile than the lightweight seats, as found by Reilly. If it has not been done, it seems advisable to test such seats with different sized dummies to verify that they provide acceptable performance across the dummy occupant size spectrum.

Another potential problem for systems using profiles tuned through testing is caused by the lack of biofidelity in the available test dummies, particularly in the vertical, or $\mathrm{Z}$, direction. Obviously it would be advantageous to test all seats with dummies specifically designed and developed to simulate human response, especially to impact loading in the vertical (Z) direction. A test dummy designed and certified to simulate human response in the vertical direction ( $\mathrm{Z}$ axis) is not yet available. First Technology Safety Systems has developed the Hybrid III Aerospace manikins and they are purported to be better than most in the vertical direction. They have a straight spine and provisions for a lumbar load measurement: however, their fidelity has not, to the author's knowledge, been established with sufficient confidence to assess the efficacy of an energy absorber with a notched loadstroke profile. The presently available dummies were developed to predominately simulate loading in the forward direction for automotive use [25]. The performance of a seating system using a specific fixed profile energy absorbing system has been shown to be sensitive to occupant weight. Considering the complete range of occupants using the seat, and considering that such a seat is tuned for the vertical response of only one dummy, it would be questionable if they can provide the protection desired across the population range of civil rotorcraft occupants.

Testing with existing dummies can be aided by computer analysis where known dummy characteristics are used to verify the model and then the variables changed to known human values to help assess human performance. Analytical modeling was used to support the Simula study discussed in the Advanced Systems section of this paper and influenced the data to be more generally applicable than might otherwise be obtained from testing alone.

Seats using the fixed profile energy absorber that have been qualified for military use have been tested with the complete range of occupant weights, also using the existing test dummies. Computer simulation was used by Skyline to aid in the development of the energy absorber with its unique load-deflection profile for the UH-1Y troop seat. It will be noted that the profile presented for the Skyline troop seat, Figure 35, developed and qualified in this way, had a significantly different profile than did that proposed by Carr, and Phillips.

Nevertheless, and in spite of the concerns mentioned above, the progress shown by the developers of the current energy absorbing seats is evidence of the efforts being concentrated on developing more sophisticated and effective energy absorbing systems that meet the current requirements. The resulting seats are desirable to the users; because, the seats use less of the space available in the aircraft and in some cases allow briefcases to be stored under the seats. However, it is the opinion of this author that the practice of storing items under the seats should be discontinued, at least until the performance of these systems has been verified across the complete spectrum of occupant sizes. Also, it was, and remains, the opinion of this author that energy absorbing seats should always be designed to stroke completely to the floor to maximize the protection provided the occupant. If the crash is a little more severe than specified, or if the occupant is heavier than the $50^{\text {th }}$ percentile male, the seat will 
reach the bottom of its stroke and either strike stops or the articles stored under the seat, increasing the risk of, and severity of injury.

It is stressed here that the possible problems discussed are related to the certification procedures that require testing with only one size of dummy, the $50^{\text {th }}$ percentile, coupled with the lack of dummies designed to adequately simulate the response of a human in the critical direction, the vertical direction. Based on previous work and observations made of current efforts, this is an area that needs to be addressed. First, a research effort is needed to assess the scope and magnitude of the potential problem. The problem could then be resolved through a change of regulations or, perhaps more expediently, through the development of a new Advisory Circular that provides guidance on how to meet the spirit of the rules.

It must be emphasized that the first step is to develop a comprehensive understanding of the effects of manikin size, crash pulse severity, seating configuration, and energy absorber characteristics. The second step is to categorize all of the data developed in step one and combined with meaningful historical data develop a basis for and a draft of certification guidance. The third step is to develop an official and/or industry guidance that will serve to meet the spirit of the regulations while assuring a safer environment for civil helicopter occupants. The end result will be that the same philosophy that has been successfully applied to military helicopters will be applied to civil helicopters, but at levels that are appropriate for the crash environment and the civil helicopter occupant population.

\section{Military Qualification Requirements}

With MIL-STD-1290 [26] and MIL-S-58095 [6] active, appropriate crash safety requirements were in place to ensure needed levels of crashworthiness in new military helicopters. With the cancellation of military specifications as well as standards, and with the current philosophy that allows everything to be traded off, the aviation community is in danger of retrograding to the aircraft crash safety levels of the 1950's. Certain cases did exist where "Mil Specs" were detrimental in that better commercial products were available for far lower prices than were procured through use of the Mil Specs. However that was not the case with safety. As has been learned too many times in the past, if minimum levels of safety are not mandated, they will be "traded off" and safety will suffer. As a result, the military is in danger of losing ground in the field of crash safety, ground that was gained through decades of effort with the payoff evidenced in the crash safety records of the newer fleet of helicopters. The Black Hawk was designed and built to modern crashworthiness standards and is an outstanding example of performance with crashworthiness. Those involved with trade off decisions need to consider the penalty involved in trading off crash safety for other desirables. The loss of a trained and experienced pilot is hard to assess, but the real number is in the millions of dollars considering the time and expense of training the individual, the time and expense it took to accumulate the experience, and the loss of time it takes to replace the capability. This, of course, is in addition to the personal tragedy associated with the loss of human life.

\section{CONCLUSIONS}

The following conclusions were reached:

1. The early work in developing various design concepts for absorbing energy in crashworthy seats has evolved into usable systems. Several different concepts have undergone further design and development and have been fielded in today's helicopters.

2. The energy absorbing devices that are being used successfully today are the Inversion Tube, the Wire Bender, the Strap Bender, the Tube and Die, and the Metal Cutter. Each seat supplier has developed their own unique design of one or more of the concepts and some have been patented.

3. Fielded crashworthy seats that have been involved in crashes have performed well and have proven their ability to protect the occupants.

4. The evolutionary process of energy absorbers for crashworthy seating has passed through several generations of development and sophistication. The first generation was the Fixed Load Energy Absorber (FLEA) that provided a constant load with stroke. The second generation consisted of two separate types both developed to achieve increased 
efficiency. The first was the Variable Load Energy Absorber (VLEA) developed to allow the limit load of the device to be varied to match the weight of the specific occupant and to thus provide equal protection to all occupants regardless of weight. The second was the Fixed Profile Energy Absorber (FPEA) which was developed to increase the seat's stroking efficiency, and specifically, to use less stroke. This option of course was attractive, especially to civil helicopter operators as it used less of the available space in the cabin of the helicopter. The third generation, the Advanced Energy Absorber, or AEA attempted to combine all of the desirable features of the first two generations. It combined the advantages of the Variable Load Energy Absorber with that of the Fixed Profile. It goes further in that it eliminates the possibility of human error in setting the device for the appropriate occupant weight by performing the weighing function and the adjustment function automatically. Conceptually it is the ultimate energy absorbing system providing the optimum protection to all occupants regardless of their weight. It is rather complex which may discourage its use, at least in the immediate future, until a more detailed producibility design effort has been performed on the concept as applied to a specific seat system. When the complexity has been reduced to warrant the benefit to be derived on a cost benefit-basis, it will provide the best protection that can be achieved in these types of crashworthy seats.

5. A problem likely exists with certification regulations for civil seats in that the required testing is accomplished using only one sized test dummy, the $50^{\text {th }}$ percentile. Strokeefficient systems using fixed profile loaddeflection characteristics (FPEA) are sensitive to the characteristics of occupant weight variations. The effect of the weight range of potential occupants may not have been adequately assessed on civil seats. This potential problem needs to be assessed and resolved appropriately if found to exist.
6. To aid in the qualification and certification processes, and in particular for seats using the fixed profile energy absorber approach, test dummies need to be developed that more accurately simulate the response of humans when dynamically loaded in the vertical, or $\mathrm{Z}$ direction.

\section{ACKNOWLEDGMENTS}

The cooperation of the seat suppliers in providing information descriptive of their seats and energy absorbing systems was greatly appreciated. The information presented in this paper was provided voluntarily to advance the quality and hopefully the usefulness of the paper and consequently differs somewhat from source to source. Those companies providing information include: Simula Inc., Phoenix, Arizona; Martin Baker Aircraft Company, Ltd, England; Fischer + Entwicklungen GmbH \& Co. KG, Germany; IAI Golan Industries, Israel Aircraft Industries Ltd., Israel; and Skyline Industries, Inc., Fort Worth, Texas.

All of the artwork was prepared by Dennis Weiher, DRW Creative Designs, Queen Creek, Arizona. Telephone: (480) 250 - 7951. Further, Lindley W. Bark, MSC.Software was of great help in reading and reviewing the manuscript, in providing many helpful comments and suggestions, formatting, integrating, and submitting the rather large file to the AHS web site for paper submittals.

\section{REFERENCES}

1. Report - Turnbow, J. W., Ph.D., et al, "Crash Survival Design Guide”, AvSer 66-18, USAAVLABS Technical Report 67-22-, Fort Eustis, Virginia, July 1967.

2. Report - Turnbow, J. W., Ph.D., et al, "Crash Survival Design Guide”, USAAVLABS Technical Report 70-22, Fort Eustis, Virginia, August 1969.

3. Report - Turnbow, J. W., Ph. D., et al, "Crash Survival Design Guide”, USAAMRDL Technical Report 71-22, Fort Eustis, Virginia, October, 1971. 
4. Report - Desjardins, S. P., et al., "Aircraft Crash Survival Design Guide”, USARTL (AVRADCOM) Technical Report 79-22, Fort Eustis, Virginia, 1980.

5. Report - Desjardins, S. P., et al, "Aircraft Crash Survival Design Guide”, Aviation Applied Technology Directorate, USAAVSCOM Technical Report 89-D-22D, Fort Eustis, Virginia, December, 1989.

6. Military Specification - MIL-S-58095A (AV), "Seat System: Crash-Resistant, Non-Ejection, Aircrew, General Specification For", Department of Defense, Washington, DC, 20301, 31 January 1986.

7. Military Specification - MIL-S-85510(AS), "Military Specification, Seats, Helicopter Cabin, Crashworthy, General Specification For”, Department of Defense, Washington, DC 20301, 19 November 1981.

8. Aerospace Standard - SAE, AS8049A, "Performance Standard For Seats in Civil Rotorcraft, Transport Aircraft, and General Aviation”, Issued July 1990 and Revised September 1997.

9. United States Code of Federal Regulations, Title 14 Part 27 - "Airworthiness Standards: Normal Category Rotorcraft”, 14CFR27.562 (Subpart 562), Washington, DC, October 1, 2002.

10. United States Code of Federal Regulations, Title 14 Part 29 - "Airworthiness Standards: Transport Category Rotorcraft”, 14CFR29.562 (Subpart 562), Washington, DC, October 1, 2002.

11. Report - Eiband, A. M., "Human Tolerance to Rapidly Applied Accelerations: A Summary of the literature”, NASA Memorandum 5-19-59E, National Aeronautics and Space Administration, Washington DC, June 1959.

12. Report - Desjardins, S. P., and Harrison, H., "The Design, Fabrication, and Testing of an Integrally Armored Crashworthy Crewseat”, Dynamic Science, Division of Marshall
Industries; USAAMRDL Technical Report 7154, Eustis Directorate, U. S. Army Air Mobility Research and Development Laboratory, Fort Eustis, Virginia, January 1972, AD 742733.

13. Report - Coltman, J. W., Van Ingen, C., and Selker, F., "Crash Resistant Crewseat LimitLoad Optimization Through Dynamic Testing with Cadavers”, Simula Inc., Report No. USAAVSCOM TR-85-D-11, Aviation Applied Technology Directorate, U.S. Army Aviation Research and Technology Activity (AVSCOM), Fort Eustis, Virginia, January 1986.

14. Meeting Paper - Desjardins, S. P, Cannon, M. R., Shane, S. J., "Discussion of Transport Passenger Seat Performance Characteristics", SAE Technical Paper Series, 881378, Aerospace Technology Conference and Exposition, Anaheim, California, October 3-6, 1988.

15. Report - Farley, G. L., "Energy Absorption of Composite Materials" NASA Technical Memorandum 84638, AVRADCOM Technical Report TR-83-B-2, Structures Laboratory, U,S. Army Research and Technology Laboratories (AVRADCOM), Langley Research Center, Hampton, Virginia 23665, March 1983.

16. Bulletin - Kroell, C. K. "A Simple, Efficient, One Shot Energy Absorber", Reprint from Bulletin No. 30, Shock, Vibration and Associated Environments, Part III, February 1962, General Motors Research Laboratory, Warren, Michigan.

17. Report - Smit, T. A., and Buys, P., "Energy Absorbing Links”, Report FS-12, Royal Netherlands Aircraft Factories, Fokker, Amsterdam, The Netherlands, June 1963.

18. Report - Svoboda, C. M., and Warrick, J. C., "Design and Development of Variable-Load Energy Absorbers”, Simula Inc., Report No. NADC-80257-60, Aircraft and Crew Systems Technology Directorate, Naval Air Development Center, Warminster, Pennsylvania, 18974, June 16, 1981. 
19. Report - Domzalski, L. P., "Dynamic Performance of a Variable Load Energy Absorber”, Report No. NADC-81227-60, Aircraft and Crew Systems Technology Directorate, Naval Air Development Center, Warminster, Pennsylvania 18974, February 1982.

20. Report - Carr, R. W., and Phillips, N. S., "Definition of Design Criteria for Energy Absorption Systems", Beta Industries Incorporated, Report No. NADC-AC-7007, Naval Air Development Center, Warminster, Pennsylvania, 11 June 1970, AD 871040.

21. Report - Reilly, M. J., "Crashworthy Troop Seat Investigation", The Boeing Vertol Company; USAAMRDL Technical Report 7493, Fort Eustis, Virginia, December 1974, AD/A-007090.

22. Report - Labun, Lance C., Ph.D., "Development of an Automatic Energy Absorber System for Crashworthy Helicopter Seats”, Final Report, Simula Safety Systems, TR-97256A; Naval Air Systems Command Headquarters, Patuxent River Maryland November 28, 2000.

23. Report - Warrick, J. C., and Coltman, J. W., "Design and Development of an Automatically Controlled Variable Load Energy Absorber”, Simula Inc., Report No. NADC-82025-60, Aircraft and Crew Systems Technology Directorate, Naval Air Development Center, Warminster, Pennsylvania 18974, March 1984.

24. Paper - Shanahan, Dennis F., LTC, M.D., M. P. H., "Crash Experience of the U.S. Army Black Hawk Helicopter”, Paper Reprint from AGARD Conference Proceedings, 532, Aircraft Accidents: Trends in Aerospace Medical Investigation Techniques, 7 Rue Ancelle 92200 Neuilly Sur Seine, France.

25. United States Code of Federal Regulations, Title 14 Part 572, Chapter 5, Subpart B, Anthropomorphic Test Dummies (ATD), 49CFR572-B, Washington, DC, October 1, 2002.
26. Military Standard - MIL-STD-1290 (AV), "Light Fixed- and Rotary-Wing Aircraft Crash Resistance”, Department of Defense, Washington DC, 20301, 26 September, 1988. 